\title{
LOS RECURSOS EN DISPUTA. EL CASO DEL CONFLICTO MINERO EN RANCHO GRANDE, NICARAGUA ${ }^{1}$
}

Mario Sánchez González

Recibido: 08/03/2013 Aceptado: 08/06/2016

\begin{abstract}
Resumen
El 12 de octubre del 2015, el Gobierno de Nicaragua declaró inviable la actividad minera en el municipio de Rancho Grande, luego de una década de lucha contra la minería. Esta investigación analiza la acción colectiva del movimiento social campesino, Guardianes de Yaoska, el primero en el país que logra incidir en la decisión del Estado de Nicaragua en declarar inviable un proyecto de explotación minera metálica. Este precedente histórico es, en cierta manera, resultado de un variado repertorio de acciones contenciosas no violentas, desarrollado de manera progresiva por dicho movimiento en su lucha contra la minería, en un contexto económico nacional e internacional adverso.
\end{abstract}

Palabras clave: Rancho Grande; extractivismo; movimiento social; ecologismo de los pobres.

\begin{abstract}
On October $12^{\text {th }}, 2015$, the Nicaraguan Government declared as non-viable a mining project in Rancho Grande, Matagalpa, after a decade of anti- mining fight. This research analyzes the collective action of the peasant social movement, Guardianes de Yaoska, in Rancho Grande, which for the first time in the country, influenced the State of Nicaragua decision to declare unfeasible a metal mining project. This historic precedent is, somehow, a result of a diverse repertoire of non-violent contentious actions, progressively developed by the movement in their fight against mining in an adverse domestic and international economic context.
\end{abstract}

Keywords: Rancho Grande; Extractivism; Social Movement; environmentalism of the poor.

\section{Introducción}

Este trabajo analiza la acción colectiva del movimiento socioambiental campesino, Guardianes de Yaoska, en el Municipio de Rancho Grande, que logró incidir en la decisión del Estado de Nicaragua en declarar inviable la explotación minera metálica en el Cerro Pavón. Este precedente histórico es, en cierta manera, resultado de un variado repertorio de acciones contenciosas no violentas, desarrollado 
de manera progresiva por dicho movimiento en su lucha contra la minería, en un contexto económico nacional e internacional adverso.

A nivel nacional, la política extractivista de "movilización de recursos domésticos" desde la industria minera para el crecimiento económico, ha sido impulsada con mayor énfasis por el actual gobierno de Nicaragua (Villafuerte, 2014; Gutiérrez, 2015). Mientras que a nivel internacional por el aumento de la inversión extranjera en la industria minera (CEPAL, 2013; Veltmeyer y Petras, 2015) y la configuración de América Latina como uno de los focos de expansión de las fronteras extractivas a escala mundial por la presencia de minerales estratégicos² (Bebbington, 2007; Carvajal et al., 2015; Gómez, Jiménez y Morán, 2015; Bruckmann, 2011).

Estudios recientes en la región advierten sobre el empoderamiento y la eficacia de las estrategias de los movimientos sociales en la defensa de sus derechos socioambientales frente al extractivismo minero. Concretamente, Spalding (2014) destaca la importancia de la dimensión histórica y sociocultural de los movimientos sociales campesinos frente al extractivismo a través de tres mecanismos: (1) la influencia religiosa, como por ejemplo la Teología de la Liberación, ${ }^{3}$ que estimuló el compromiso cristiano por la acción social; (2) la experiencia política y organizativa que muchas comunidades desarrollaron en contextos adversos (como conflictos armados en Centroamérica), (3) las solidarias relaciones locales, nacionales e internacionales entre las comunidades y organizaciones que crearon los vasos comunicantes para el intercambio de experiencias y la toma de conciencia sobre los problemas del extractivismo.

Otro referente en la región es el estudio de Mojica-Mendieta (2014), que desde la decolonialidad de la naturaleza y el ecologismo de los pobres, advierte que la lucha socioambiental puede potenciar la resistencia y la movilización social en contra del extractivismo por el principio de supervivencia (Martínez-Alier, 1990, 1992, 2011); además, recalca la importancia de la comunicación intercultural y el liderazgo político en esta clase de contiendas que provocan nuevos saberes ambientales.

En torno al caso de Rancho Grande, Serjeant (2015) analiza el impacto expansivo que provoca la penetración de una transnacional minera en una de sus comunidades, y la respuesta social que se genera a través de la emergencia del movimiento Guardianes de Yaoska. Estos aprovecharon creativamente su capacidad de agencia para cambiar las relaciones dominantes en un contexto de amenaza, caracterizado por el desgate político de las autoridades locales. Al mismo tiempo, Pérez (2015) aborda dos aspectos sensibles en torno al conflicto minero en Rancho Grande: (1) la relación entre extractivismo y desarrollo, ${ }^{4}$ y (2) el papel pacificador y organizador que jugaron las mujeres en la lucha del movimiento Guardianes de Yaoska, a pesar de las prevalecientes brechas de género en el liderazgo.

La revisión sucinta de estas investigaciones aporta valiosos insumos para el estudio de los movimientos sociales contra el extractivismo minero, en particular: 
1. Desde la teoría de los movimientos sociales, Spalding $(2014,2016)$ analiza la interacción entre las compañías mineras, las élites políticas y los movimientos de resistencia contra la minería en Centroamérica. ${ }^{5}$ Desarrolla un análisis del impacto diferenciado de los movimientos sociales en las políticas mineras de la región, considerando tres elementos generales: a) la forma y el alcance de las redes de resistencia contra la minería, b) la extensión y durabilidad de la cohesión de las élites, y c) El acceso a los espacios o puntos de articulación entre los movimientos sociales con las instituciones públicas, que permiten incorporar las demandas de estos últimos, en contexto de contiendas electorales o procesos judiciales.

2. La dimensión del impacto que representa la penetración y el desarrollo de un proyecto extractivista minero -en alianza con el Estado- en un contexto rural y eminentemente agropecuario, $\mathrm{y}$, a su vez, la capacidad de respuesta de los actores sociales para cambiar la correlación de fuerzas en su contexto político, según Serjeant (2015).

3. El análisis desde la decolonialidad de la naturaleza y los saberes propone revalorar la dimensión política y cultural del "ecologismo de los pobres"6 (Martínez-Alier, 1990, 1992, 2011) y la "politización de la naturaleza" (PortoGonçalves, 2009, 131).

4. La reflexión crítica en torno a la "relación" entre extractivismo y desarrollo en Rancho Grande (Pérez, 2015) sugiere politizar la discusión sobre los modelos de desarrollo en el marco de los conflictos socioambientales y su contienda política. Además reconoce el rol activo que juegan las mujeres en estas contiendas.

Al asumir la relevancia de la problemática del extractivismo en las sociedades latinoamericanos, a partir de estos referentes teóricos y sus contribuciones, interesa precisar la importancia y el valor que representa estudiar la experiencia exitosa de la lucha campesina contra la minería en Rancho Grande en un país como Nicaragua; en cuyo contexto se advierte una creciente tensión entre la apuesta política y económica del actual Gobierno por el neoextractivismo ${ }^{8}$ (en alianzas con las empresas mineras transnacionales) y la resistencia de movimientos sociales en defensa de los derechos socioambientales (Sánchez al., 2015), ${ }^{9}$ económicos y laborales. Para entender mejor lo que representa la lucha del movimiento Guardianes de Yaoska y sus resultados, es importante contextualizar la apuesta política y económica del actual gobierno de Nicaragua por el extractivismo, así como la forma autoritaria y represiva con la que dicho gobierno ha administrado los conflictos en torno a la actividad minera.

\section{"Nicaragua es un país minero"10}

"Nicaragua es un país minero", estas son las palabras de Pablo Venturo, gerente de de la transnacional canadiense B2Gold, al referirse a la nueva realidad que representa el país centroamericano en términos de crecimiento de la actividad minera 
y de las condiciones favorables para la inversión de este sector extractivo. El Plan de Desarrollo Humano del Gobierno de Nicaragua (PDHN) establece una política de fomento de la minería que "contribuya al desarrollo del país, con enfoque de equidad en cuanto a los beneficios tanto para el inversionista extranjero o nacional -Estado y sociedad" (PNDH, 2012: 127). Según este plan se tiene previsto que en el quinquenio 2012-2017, la producción de onzas de oro supere el millón (Pérez, 2015). A pesar de una sensible disminución en la producción nacional del oro en el año 2015, la cifras oficiales indican que en los últimos ocho años, la producción nacional de oro se ha triplicado (gráfico 1); así mismo, el número de concesiones se ha incrementado de 189 en el 2007 a 298 en el 2014 (Ministerio de Energía y Minas, 2014).

Gráfico 1

PRODUCCIÓN NACIONAL DE ORO

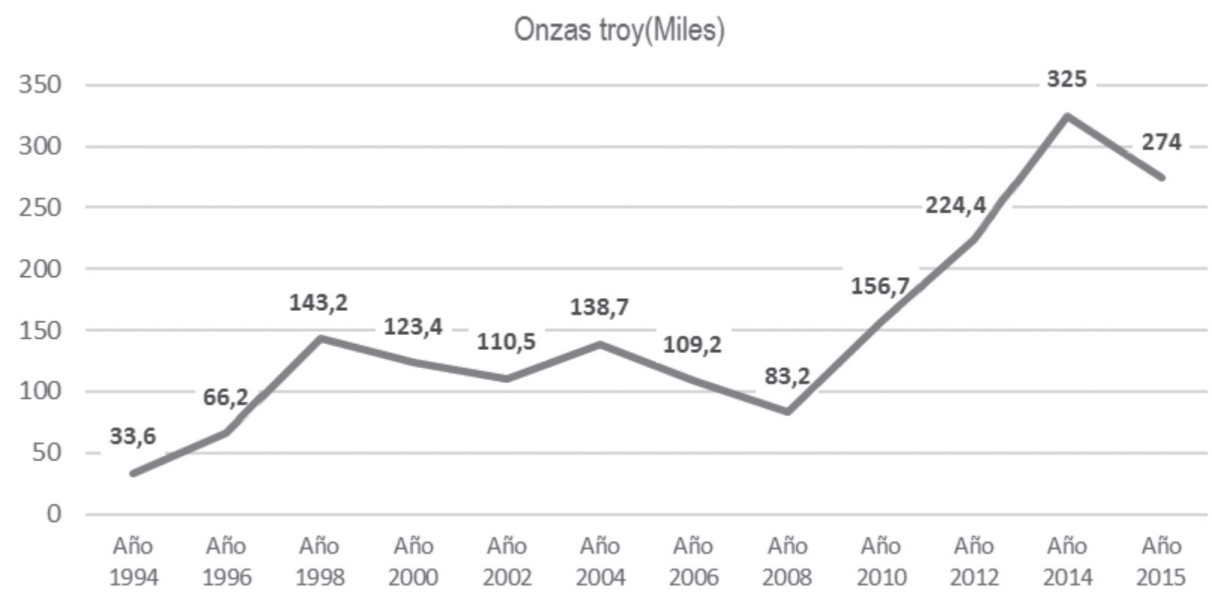

Fuente: Banco Central de Nicaragua.

En virtud de los lineamientos políticos del gobierno de Nicaragua, la promoción del sector minero ante la inversión extranjera ha sido una de las principales prioridades de su gestión. De acuerdo con estas directrices, la agencia gubernamental de promoción de inversiones PRONicaragua, ${ }^{11}$ en alianza con el sector empresarial del país y las compañías transnacionales mineras, organizaron el Primer Congreso Internacional de Minería ${ }^{12}$ en Managua, del 12 al 14 de agosto del 2014. En uno de sus documentos promocionales, "Nicaragua, Discover the Mining Opportunities", se señala que el 49,18 por ciento de la superficie del país $(64120,36$ km²), "está disponible" para concesiones mineras y que, además, la nación ofrece condiciones jurídicas y fiscales favorables para la inversión ${ }^{13}$ (PRONicaragua, 2015). Estas políticas a favor de la minería han contribuido al rápido incremento de la inversión extranjera directa. Sin embargo, 
precisa reconocer que esta expansión de dicha actividad ha chocado con otras realidades debido a su impacto e implicaciones socioambientales. Al menos, el 17 por ciento de las concesiones activas del país se encuentran en zonas de alta fragilidad ambiental, como áreas protegidas..$^{14}$ En muchas de estas reservas o áreas de vulnerabilidad ambiental habitan poblaciones indígenas y comunidades campesinas, que se resisten y oponen a la destrucción de sus ecosistemas y medios de vida por la actividad extractiva. De ahí las conflictividades en torno a la minería y la respuesta del Gobierno a las movilizaciones sociales.

\section{Conflictos mineros y la desarticulación de la protesta}

Otro elemento crítico de la actividad minera se refiere a los conflictos desde la perspectiva laboral y económica (Cuadro 1). Muchas de estas dinámicas contenciosas han escalado en situaciones de violencia y procesos de judicialización en contra de algunos líderes de los grupos contenciosos, específicamente los conflictos mineros de Santo Domingo, Bonanza y El Limón. 


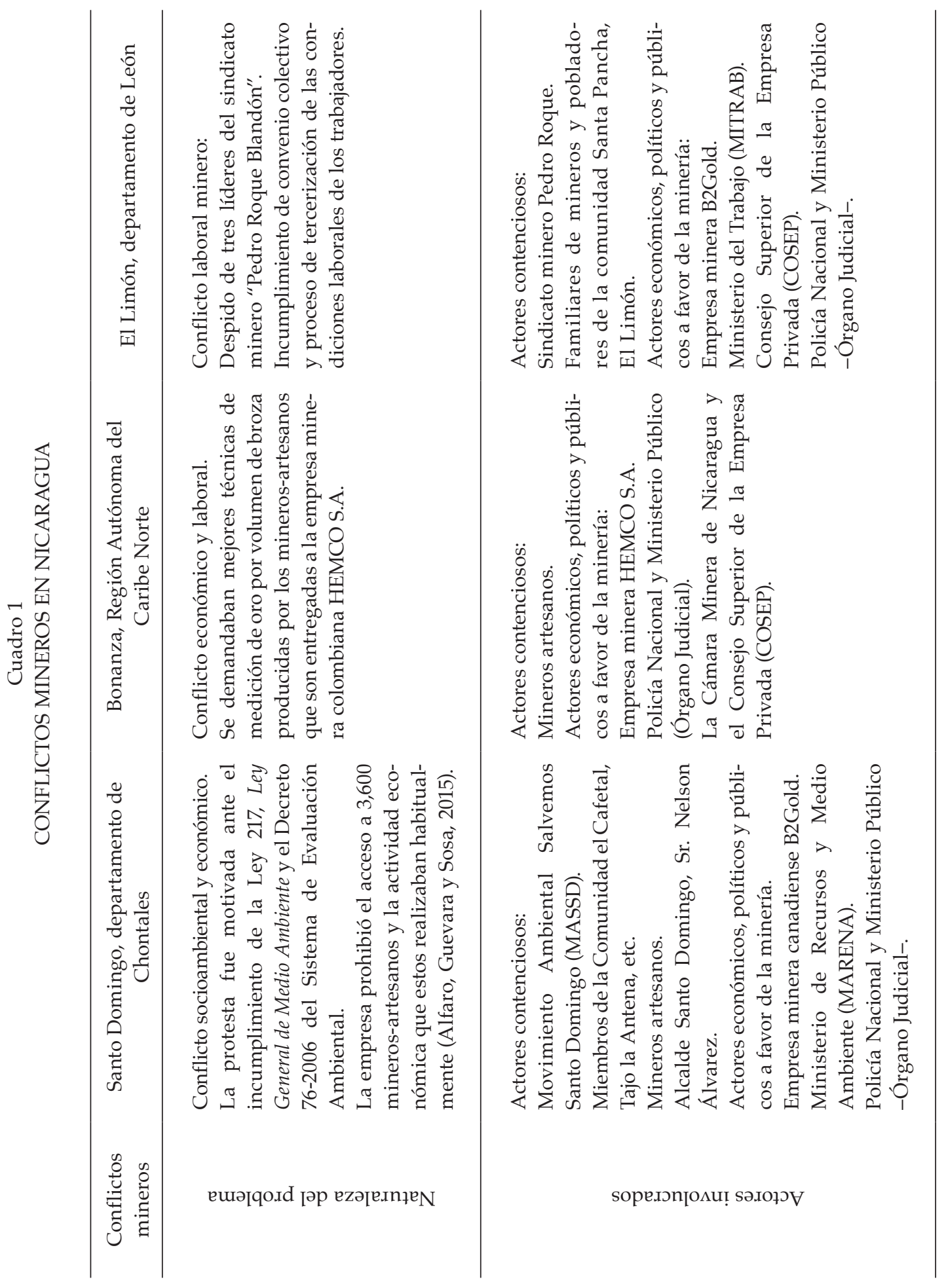




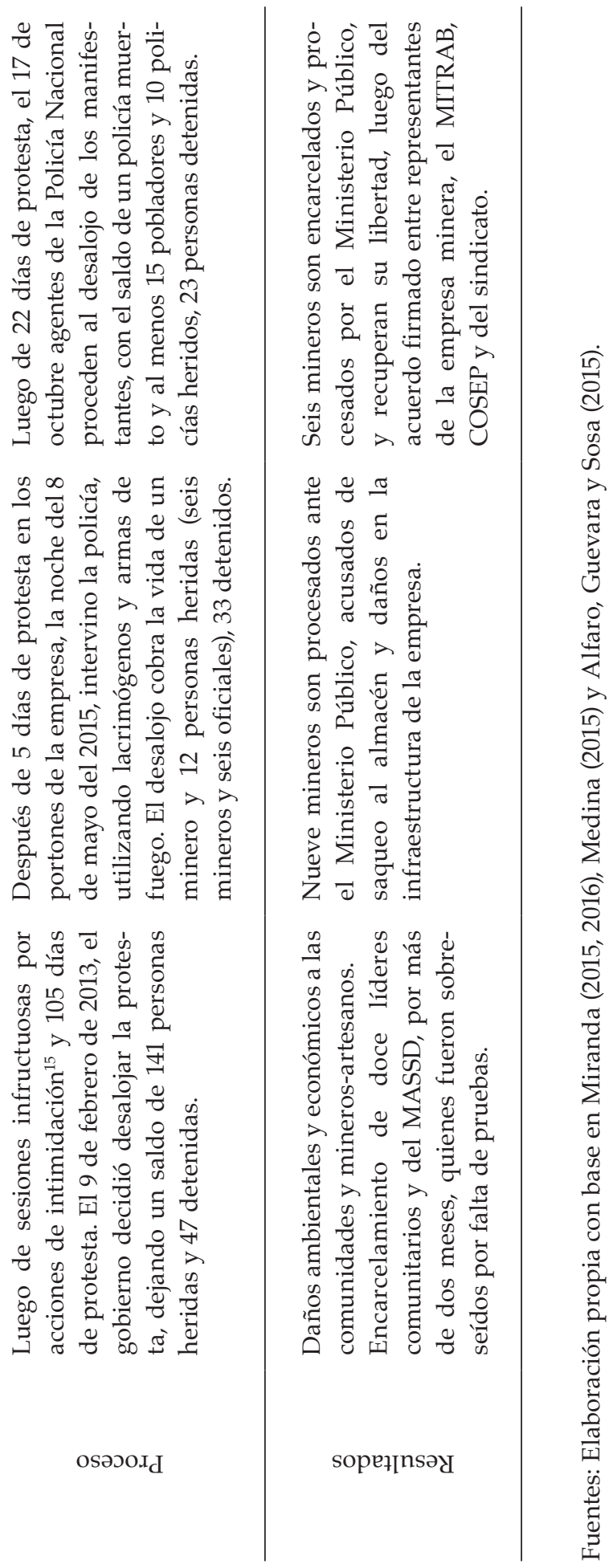


Además de la escalada de violencia de estos conflictos, el Centro Nicaragüense de Derechos Humanos (CENIDH) ha denunciado, ante la Comisión Interamericana de Derechos Humanos (CIDH) ${ }^{16}$ la instrumentalización de los operadores de justicia para desarticular la protesta social de los pequeños mineros y líderes de movimientos ambientales. Concretamente, se señaló la articulación entre la Policía, el Poder Judicial, las autoridades públicas y las empresas, con la finalidad de garantizar los intereses económicos de estas últimas, en detrimento de los derechos humanos y ambientales de líderes y miembros de las comunidades afectadas.

Frente a esta compleja realidad, de un Gobierno empeñado en promover la actividad minera y de gestionar las conflictividades con tácticas represivas, se torna necesario discernir formas de acción colectiva cuya contienda política ha logrado detener el avance y penetración de la actividad minera. De ahí el interés de analizar cuáles condiciones posibilitaron que el movimiento social Guardianes de Yaoska en Rancho Grande transitara de un conflicto socioambiental a una contienda política transgresiva y efectiva.

Para responder a esta pregunta de investigación se adopta un enfoque cualitativo centrado en el análisis sociohistórico de las acciones colectivas que se desarrollaron en el municipio de Rancho Grande, Matagalpa, durante el periodo 2004-2015. Por un lado, se toma como punto de partida el 2004, porque fue el momento cuando se iniciaron las primeras acciones de protesta en contra de la concesión minera que de forma inconsulta había sido otorgada por el Estado de Nicaragua a la Compañía Canadiense MINESA. Por otro lado, se delimitó como punto de llegada el 12 de octubre del 2015, pues fue cuando se declara inviable la explotación minera en el Cerro Pavón -comunidad de Yaoska del Municipio de Rancho Grande-.

Ante esto, se tornó necesario combinar un conjunto de estrategias para la recolección de datos: 1) observación participante, 2) revisión documental y hemerográfica de los principales medios de comunicación escritos y digitales de Nicaragua: La Prensa, El Nuevo Diario, Confidencial y El 19 Digital (medio digital de comunicación del Gobierno de Nicaragua); 3) entrevistas exploratorias a estudiosos ${ }^{17}$ de la materia, 4) entrevistas en profundidad a actores del movimiento social (líderes fundadores y miembros del movimiento Guardianes de Yaoska, líderes religiosos de las Iglesias católica y evangélica, miembros de organizaciones sociales que conforman el Grupo Estratégico de Matagalpa ${ }^{18}$ (GEM). La mayoría de las entrevistas al liderazgo de Guardianes de Yaoska se realizaron en la oficina ubicada en el municipio de Rancho Grande, para aprovechar sus asambleas generales en donde participaban los representantes de todas las comunidades. En cambio, las entrevistas a los miembros del GEM se llevaron a cabo en las oficinas de cada una de las instituciones. Es decir, en contextos familiares para las personas informantes. La información generada se procesó de forma estructurada en categorías y nodos a través del software MaxQDA versión 12. 
En términos generales, la investigación se sustenta principalmente en la propuesta teórica del análisis sociohistórico de las acciones colectivas sobre los movimientos sociales (McAdam, Tarrow y Tilly, 2005; Tarrow, 1997) en un contexto de conflictividad social prolongado (Azar, 1990). Además, el abordaje teórico se enriqueció con la categoría del "ecologismo de los pobres" (Martínez-Alier, 1990, 1992, 2011). El análisis de los resultados se organizó en una ruta de cuatro estaciones: a) Contexto del movimiento Guardianes de Yaoska, b) La opción ecológica de la Iglesia y el ecologismo de los pobres: raíces y fortalezas del movimiento social, c) El adversario: su genoma de "violencia colonial", y d) El efecto "cigarra".

\section{Naturaleza y contexto del movimiento de los Guardianes de Yaoska}

Antes de describir el contexto en donde surge el movimiento campesino Guardianes de Yaoska, se señalarán, brevemente, sus características. Esta es una organización que cuenta con la participación de liderazgos comunitarios de las treinta y ocho comunidades del Municipio de Rancho Grande, con una directiva de cinco miembros, catorce comisiones orientadas a la formación y sensibilización ambiental, comunicación e información, coordinación de acciones de incidencia, entre otras. A juicio de Juan Carlos Arce, miembro del CENIDH-Matagalpa, el movimiento Guardianes de Yaoska tiene la capacidad de "movilizar a miles de personas en un municipio eminentemente rural, con unas 49 mil personas en comunidades, bastante distantes unas de otras [con un elemento de] concientización, cara a cara, casa a casa, comunidad a comunidad, con la gente" (Equipo Envío, 2014: párr. 38).

Este movimiento supo mantener y aprovechar su autonomía gracias al espíritu de sacrificio y amplio nivel de participación de sus miembros y colaboradores, dado que no contaban con recursos para llevar a cabo sus actividades y procesos de formación e información. Como bien señala Eulogio Dávila, miembro de Guardianes de Yaoska:

Para esta lucha nosotros no [dependimos] de ninguna organización que nos patrocine plata o que nos patrocine una camioneta para ir a una reunión o una marcha. Nosotros nos movilizamos caminando una, hasta cuatro horas de camino, para llevarle la información a cada campesino, a cada productor que necesita saber la realidad. Y sin distinción de nada: ahí vamos mujeres y hombres de todos credos políticos, de todas religiones (Equipo Envío, 2014: párr. 39).

El contexto donde se desarrolló este movimiento social campesino es Rancho Grande, un municipio eminentemente rural, con una población aproximada de 49730 habitantes (INIDE, 2005), cuya base económica se centra en la "producción y comercialización agropecuaria, principalmente de café, cacao, así como de arroz, malanga, yuca, naranja, mandarina, aguacate, pijibay, chayote", entre otros productos (Sosa, 2015: s. p.). Las buenas prácticas en agricultura sostenibles, ${ }^{19}$ junto con 
las condiciones del clima y del suelo, han propiciado un entorno favorable para la producción agrícola que garantiza el abastecimiento de la comunidad y su eventual comercialización y hasta exportación (como la introducción del cacao al mercado alemán). ${ }^{20}$

Figura 1

\section{MACRO Y MICRO LOCALIZACIÓN DE RANCHO GRANDE}

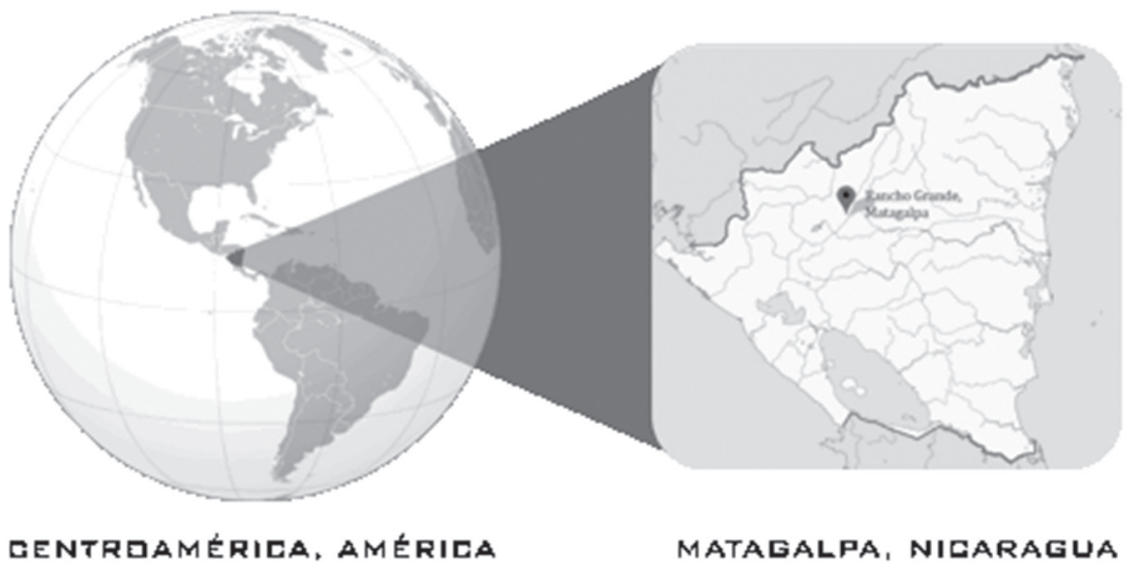

Fuente: Elaboración de Néstor López Irías.

A pesar de la transición de prácticas de agricultura sostenible en muchas parcelas familiares, cooperativas y grupos solidarios de productores, Rancho Grande sigue siendo un municipio cuya población se encuentra en situación de pobreza ${ }^{21}$ (INIDE, 2005; Ministerio de Agropecuario y Forestal, 2012). La población ranchograndeña económicamente activa es casi del $43,7 \%$. El sector que más genera trabajo es el primario $(85,32 \%)$, de los cuales el 95,61\% corresponde a los hombres y el 4,38\%, a las mujeres. El 90,3\% de la población se encuentra en condición de pobreza, de los cuales el 21,7 \% está en situación de pobreza general y el 68,6 \% en extrema. El índice de hacinamiento en el municipio es del 39,9\%, el de servicios insuficientes de $60,8 \%$, el de vivienda inadecuada de $27,1 \%$ y el de baja educación de $49,9 \% .^{22}$

Una de las bondades del municipio es que su ecosistema forma parte de la Reserva Natural Macizo de Peñas Blancas, una de las seis áreas protegidas que conforman el núcleo de la Reserva de Biósfera de Bosawas. ${ }^{23}$ En términos hídricos, su principal río es la subcuenca del río Yaoska, que a su vez forma parte de la cuenca del Río Grande de Matagalpa, cuyo caudal desemboca en la vertiente del Atlántico, con un recorrido que abarca 35 municipios de 6 departamentos. Otros ríos, de suma importancia para la vida de los ranchograndeños, son Manceras, Kiwaska y Babaska, que cruzan a lo largo y ancho el municipio de Rancho Grande. En resumen, este cuenta con abundantes recursos hídricos para el consumo humano y la producción. 
El proyecto minero

A pesar de este entorno dinámicamente productivo, de la persistente situación de pobreza que sufre la población ranchograndeña y las bondades de su ecosistema, el Gobierno de Nicaragua otorgó a la empresa canadiense Empresa Minerales de Nicaragua S.A. (MINESA) una extensión de 49000 hectáreas (ha), lo que abarca Rancho Grande y los municipios vecinos de Waslala (RACCN) y San José Bocay (Jinotega). Cuatro años después de la fase de exploración, la concesión se redujo a un área de 1301,10 ha (Ministerio de Energía y Minas, citado por Sosa, 2015). En el 2010, MINESA vendió sus derechos a otra empresa canadiense, Minerales Nueva Esperanza S.A., subsidiaria de la transnacional B2Gold -con sede en Vancouver, Canadá-. A partir de ese momento se inició el proyecto de exploración llamado "El Pavón", el cual consistió en una ofensiva de penetración y "campaña social", a fin de conseguir la licencia social necesaria para desarrollar progresivamente sus operaciones extractivas (Gutiérrez, 2015). Estos procesos de concesión fueron inconsultos, sin la participación de las comunidades potencialmente afectadas, y se eludieron procesos administrativos establecidos en la legislación nacional, como la Ley 217 Ley General de Medio Ambiente y el Decreto 76-2006 del Sistema de Evaluación Ambiental. ${ }^{24}$ Todo esto a pesar de que el Concejo Municipal había emitido dos resoluciones en contra de dichas concesiones, en aras de proteger las distintas cuencas hidrográficas de la zona:

1) Resolución del 23 de noviembre de 2010 sobre el lote de 4711 ha, ubicadas en la parte alta del río Babaska, río Manceras, río El Chancho y río Yaoska.

2) Resolución del 11 de julio del 2012 en rechazo del lote de 48604 ha, ubicadas en los sectores río Bijao, Kiwaska, El Tuma, Bilampí, Caño Negro y los afluentes de los ríos Yaoska y El Tuma (Sosa, 2015). 
Excurso 1

EL IMPACTO ECONÓMICO REAL DE LA MINERÍA EN NICARAGUA

La minería metálica, desde que irrumpió en Nicaragua hasta la fecha, ${ }^{25}$ se ha caracterizado por ser una economía de enclave orientada al mercado internacional y a la acumulación de riqueza (Padilla, 2014), y ha sido una industria depredadora de recursos y medios de vida, ${ }^{26}$ que genera conflictos y dinámicas polarizantes en el seno de las comunidades (Machado, 2014).

Nicaragua es el cuarto país destino para la inversión minera y el segundo en exenciones y ventajas fiscales a nivel latinoamericano (Germanwatch, 2015); hasta el año 2015 se han otorgado 277 concesiones que afectan aproximadamente al 10,5\% de la superficie nacional (Ministerio de Energías y Minas, 2015).

A pesar de que la producción y las exportaciones de oro han aumentado, esto no ha representado un beneficio directo a las economías locales. En parte, porque se trata de una actividad económica de enclave que no genera encadenamientos fiscales (Hirschamn, 1958) ni de valor (Padilla, 2014; Gutiérrez, 2015), sino que desarticula a las economías ya existentes y además genera un gravísimo impacto socioambiental en los territorios.

La minería metálica representa apenas el 1,14 \% del PIB (Banco Central de Nicaragua, 2015) y generan el 0,15\% del total de ocupados (Ministerio de Energías y Minas, 2015) y el 0,68 \% de los cotizantes del INSS.

Además de la lógica de costo/beneficio, en términos económicos, la condición de vulnerabilidad ambiental de Nicaragua, ubicada en el cuarto lugar del índice de riesgo climático, según Germanwatch (2015) y Oxfam (2014) debe ser otro criterio para discutir la viabilidad de un modelo de desarrollo extractivista, con fuerte presencia de la minería.

Fuente: Elaboración propia.

Por directrices políticas del Gobierno central, el Concejo Municipal de Rancho Grande tomó un giro radical a favor del desarrollo de la actividad minera en dicho municipio, a pesar de que una de las promesas de la campaña electoral del 2012 había sido la resistencia contra la minería. Sobre este cambio, el padre Teodoro Custer (uno de los primeros y principales motivadores del movimiento contra la minería) ${ }^{27}$ comentó que a pesar de los años, este giro le generó desconcierto:

¿Cómo puede ser? Cuando yo estaba haciendo la lucha, aquí casi solo los sandinistas locales me apoyaban y ahora que [...] están en el poder, ¿cómo puede ser eso, que cambiaron de parecer y ahora están apoyando la mina y al gobierno? (Teodoro Custer, comunicación personal, 30 noviembre del 2015).

El padre Custer, consciente de los efectos de actividad minera por la experiencia de las hermanas Maryknoll en Guatemala, desarrolló distintas acciones orientadas a promover la concienciación y organización de las comunidades a través de los líderes 
eclesiales. $^{28} \mathrm{Su}$ mayor preocupación era evitar la penetración de la empresa minera en el municipio. Posteriormente, la Asociación para la Diversificación y el Desarrollo Agrícola Comunal (ADDAC) se interesó en el esfuerzo que impulsaba la parroquia y asumió un intenso trabajo de sensibilización y fortalecimiento organizativo frente a la problemática de la minería.

En esta línea, el acceso y la divulgación a la información en las comunidades fue un mecanismo que motivó la organización, movilización y empoderamiento del movimiento social. En estos términos, Ernesto Montenegro, uno de los líderes y fundadores de Guardianes de Yaoska, comentó:

Algo que nos ayudó mucho fue la buena información de ADDAC, que tiene aqui organizadas 38 comunidades. Tal vez nosotros no habiamos nacido como comisión pero ADDAC ya le estaba informando a la gente lo malo que era la mina (Ernesto Montenegro, comunicación personal, 30 noviembre del 2015).

De esta manera, inició un intenso proceso de sensibilización e intercambio de experiencias sobre los efectos de la explotación minera con miembros de comunidades afectadas por la minería metálica en Nicaragua, El Salvador, Honduras y Guatemala. Tanto organizaciones de desarrollo como líderes religiosos asumieron un rol activo y multiplicador en la sensibilización, como lo manifiesta una delegada de la palabra ${ }^{29}$ de la comunidad de San Antonio de Kuskawas: "Somos testigos que donde ha entrado la minería hay mucha destrucción y muchos lamentos, entonces nosotros en eso nos basamos" (Elizabeth Chavarría, comunicación personal, 29 de noviembre del 2015). Un elemento clave en el surgimiento del movimiento social Guardianes de Yaoska fue el acceso y propagación de la información; sobre todo, la procedente de otras comunidades afectadas por la industria minera. Este tipo de estrategia, de ver el desastre socioambiental en otras comunidades, funciona como "terapia de choque" que, a juicio de Rodríguez y Hesse, "brinda la oportunidad a la gente de desarrollar una mayor capacidad de observación, comparación y análisis" (2000: 62). En otras palabras, contribuye a discernir las causas y efectos de los problemas ambientales y a motivar la movilización, tal como lo manifiesta una de las fundadoras del Movimiento Guardianes de Yaoska:

A mí me motivó mucho mirar la mina El Limón [y] Santa Pancha. Conocí también la mina de Chontales, entonces me hirió mucho, y pensé que no sería justo, que aquí en Rancho Grande, siendo un municipio tan bello, con tanto paisajes, vinieran a hacer la misma grosería que han hecho en otros municipios. Entonces yo me he impulsado a la lucha, no me he parado, no me he detenido (Juana Loáisiga, comunicación personal, 30 de noviembre del 2015).

Este sostenido proceso de información, sensibilización y divulgación se conoce en la teoría de la acción colectica como "correduría” (McAdam, Tarrow y Tilly, 2005), 
el cual se refiere a un mecanismo aprovechado por Guardianes de Yaoska en su alianza con el Grupo Estratégico de Matagalpa. Uno de sus miembros del GEM afirma que a partir de este mecanismo, las personas se posicionaron frente a los daños irreversibles de la actividad minera: "A la gente no le das atol con el dedo ${ }^{30}(.$.$) , sabe y entiende lo$ que implica una actividad de esa envergadura en un territorio" (Juan Herrera, comunicación personal, 14 de noviembre de 2015).

En un contexto adverso, en el cual la alianza entre la empresa minera y el Gobierno arrecian su campaña social; el liderazgo católico y comunitario, junto con las organizaciones no gubernamentales, articularon esfuerzos de sensibilización, formación y divulgación sobre los riesgos de la industria minera en el territorio. Este dinamismo abonó, en cierta manera, a la cohesión del movimiento Guardianes de Yaoska y al empoderamiento de las comunidades en su lucha contra el proyecto minero. Como se observará en el siguiente acápite, la incorporación del discurso medioambiental dentro del marco religioso de las iglesias no solo se produce gracias a la tradición ecológica del cristianismo en su doctrina social, sino a las prácticas de acompañamiento pastoral (Wilde, 2015).

\section{La opción ecológica de la Iglesia y el ecologismo de los pobres: raíces y fortalezas del movimiento social}

Son diversas las expresiones de la tradición cristiana en favor del medio ambiente, algunas basadas en la ecoteología (Boff, 1996, 2008), otras en la doctrina social de la iglesia -Documento de Aparecida (CELAM, 2007)- y la Encíclica "Laudato Si" (Francisco, 2015). Estas declaraciones eclesiales apoyan el discurso y las prácticas de Guardianes de Yaoska y sus aliados, al igual que critican el argumento del progreso minero promulgado por la Alianza Empresa Minera-Estado.

Estudios como el de Spalding (2015), en torno al caso de El Salvador y el de Arellano-Yanguas (2015) en Perú, reconocen que la tradición de ciertos sectores del catolicismo por la protección del medioambiente juega un papel importante en los procesos de movilización social contra la minería. Además, señalan que "la incorporación dentro del discurso religioso de lógicas ambientales y de derechos humanos ha ayudado a legitimar las movilizaciones populares" (Arellano-Yanguas, 2015: 324). Este discurso religioso con contenido ecológico en la Iglesia católica se inspira o fundamenta desde distintas fuentes doctrinales, como el pensamiento bíblico-teológico y documentos eclesiales. En el caso de la Diócesis de Matagalpa, el obispo, Rolando Álvarez, ${ }^{31}$ argumenta la opción cristiana por la defensa del medio ambiente en la teología bíblica, como se puede apreciar en la siguiente reflexión: "son hechos bíblicos que nos motivaron y nos animaron a tener conciencia de ser custodios de esa creación" (Monseñor Rolando Álvarez, comunicación personal, 28 de noviembre del 2015). 
Otro referente doctrinario del cristianismo, que validó la defensa del medio ambiente en contra de la minería, fue la Carta Encíclica "Laudato Si", que a juicio de monseñor Álvarez:

Vino a ratificar nuestra lucha y nuestro esfuerzo por el bien común de la población en Rancho Grande. Vino a consolidar la mística que teníamos. Vino alargar aún más nuestros horizontes y, por supuesto, a darnos una mayor esperanza de la posibilidad de luchar y lograr lo que nos proponíamos, y de lo que estamos convencidos de que era y sigue siendo lo correcto y lo justo (Monseñor Rolando Álvarez, comunicación personal, 28 de noviembre del 2015).

Además del cuerpo doctrinal, la jerarquía y el liderazgo eclesial tenían claro que el conflicto de Rancho Grande era un asunto real y de supervivencia para sus habitantes, cuya gravedad comprometió aún más a la Iglesia, según lo manifiesta el vicario general de la Diócesis de Matagalpa, Monseñor Edgar Sacasa: ${ }^{32}$

(...) la iglesia es ecologista y además nuestras ovejas están ahí. El caso de Rancho Grande, es un caso que llegamos a comprender que era un caso de vida o muerte. Además sentíamos que era un engaño institucional, de un proyecto desarrollista que pretendia venderle a la gente un canto de sirena, ${ }^{33}$ como dicen, un espejito. El pueblo nos atrajo, no podiamos fallarle; si no íbamos, ya no teníamos más que ir [a] hacer. No podíamos no ir, yo diría que el pueblo nos comprometió (Monseñor Edgard Sacasa, comunicación personal, 28 de noviembre del 2015).

Esta opción apostólica por la ecología fue un proceso que no solo implicó la incorporación de acciones en el Plan Pastoral o la creación de instancias operativas como la Comisión Diocesana de Ecología y Vida, sino un compromiso político de la Diócesis:

(...) de unos tres años para acá existe una nueva opción pastoral, que es la opción ecológica. Digamos que empieza por lo más suave, que es la reforestación, que es la construcción de viveros, la fundación de clubes ecológicos, digamos ecología en positivo. Pero lo que nos llevó en este caso, el principio espiritual bíblico por la creación de la tierra, obviamente ya es un factor nuevo. Esto ya no es un ecologismo en positivo, sino ecologismo en rebeldia, ecologismo en protesta, ecologismo que choca, que denuncia, que enfrenta a poderosos, que gracias a Dios, el gobierno ha reaccionado con la debida prudencia (Monseñor Edgard Sacasa, comunicación personal, 28 de noviembre de 2015).

En esta línea, la opción ecológica no fue exclusivamente una iniciativa de la Diócesis, sino que fue asumida de forma solidaria por la Conferencia Episcopal de Nicaragua (CEN), es decir, "el tema de Rancho Grande llegó a los niveles más altos que pueda llegar una gestión, digamos que fue apoyada y acuerpada por todos los obispos" a través de la Carta del CEN dirigida al presidente de Nicaragua, con fecha del 21 de mayo del 2014. Este tránsito de un posicionamiento local a uno nacional se conoce, 
según McAdam, Tarrow y Tilly (2005), como un cambio de escala de los movimientos sociales que los hace aún más eficaces.

Este proceso de acompañamiento al movimiento campesino "ha impactado en lo que es la identidad de la diócesis" (Monseñor Sacasa, comunicación personal, 28 de noviembre del 2015). Así mismo, en este liderazgo religioso, tanto de la Diócesis de Matagalpa como de la parroquia de Rancho Grande, se observa que la pastoral de acompañamiento les ha llevado a dar respuesta al conflicto minero, haciendo explícito su compromiso político por el medioambiente y su apoyo al liderazgo del movimiento social contra la minería. Este "hacerse cargo" de la problemática ambiental deja en evidencia el auténtico compromiso pastoral de acompañar a su feligresía frente a sus desafíos. Considerada la relevancia de esta experiencia vivida por la jerarquía y el liderazgo de la iglesia, interesa analizar otro elemento clave en el movimiento social contra la minería: el "ecologismo de los pobres".

\section{El ecologismo de los pobres y el discurso del desarrollo como estrategia de dominación}

A juicio de Martínez-Alier (1990), gran parte de los movimientos sociales emergen de las luchas de los pobres por la supervivencia, y por ello son considerados movimientos ecologistas. Estos tratan de mantener los recursos naturales fuera de la esfera económica y de la restringida valoración monetaria, dado que la relación entre sociedad y naturaleza es un asunto de diálogos o disputa de múltiples criterios, que engloba los aspectos necesarios para garantizar la vida y su reproducción.

Este principio de supervivencia empuja a los pobres a defender y a proteger sus ecosistemas, frente a algún daño ambiental o ante una posible amenaza, dado que se trata de "la necesidad ineludible de la subsistencia humana, la demanda de seguridad alimentaria y ambiental, la defensa de la identidad cultural y los derechos territoriales indígenas" (Martínez Alier, 2001: 129). Desde la perspectiva de este ecologismo, los pobres, ya sean campesinos o indígenas, están fuertemente vinculados al ecosistema, de donde obtienen su sustento y en el que han ido construyendo social y cotidianamente sus estrategias de vida. Además, en este hábitat han logrado estabilizar su relación con el ambiente y consolidar históricamente un espacio socioambiental, caracterizado por la relación sociedad-naturaleza.

Cuando un conflicto socioambiental se manifiesta en torno al problema del impacto que se produce en las condiciones de habitabilidad de los territorios, generados por la apropiación desigual de los bienes naturales y su uso destructivo (Machado, 2014), se presenta un "conflicto sobre producción de territorio". Es decir, a las siguientes disputas y definiciones: "qué tipo de relación entre sociedad y ambiente debería predominar en un territorio, cómo y por quiénes deben ser gobernados los territorios, qué significados y valores se les debe adscribir a estos territorios socialmente 
construidos" (Bebbington, 2007: 33). En este sentido, la perspectiva del ecologismo de los pobres no solo se sitúa frente a la acción colectiva de los movimientos sociales que defiende, bajo el principio de supervivencia, el acceso a los recursos naturales y a los servicios ambientales de la naturaleza, sino que posibilita problematizar los discursos y prácticas sobre el desarrollo, en tanto "estrategias de dominación cultural, social, económica y política" (Escobar, 2014: 28).

Un riesgo que subyace a la propuesta teórica del ecologismo de los pobres, como se ha hecho referencia, es el hecho de no explicitar claramente aspectos socioculturales como la agricultura sostenible y la tradición ecológica en el cristianismo, ${ }^{34}$ las cuales tienen una dimensión histórica y permiten reconocer su naturaleza progresiva. Podría decirse que al ecologismo de los pobres, en estos contextos, le antecede o sustenta una serie de procesos educativos, organizativos y de posicionamiento crítico frente a los modelos agrícolas extractivos ${ }^{35}$ los cuales, por lo general, favorecen más la maximización de los beneficios de las industrias agroquímicas y de alimentos, que la calidad de vida del campesinado en las sociedades. En el caso de Rancho Grande, y como en otras experiencias de lucha ambiental, se ha ido cultivando la idea de que la sostenibilidad de la agricultura y las estrategias de vida en el campo dependen de forma sustancial del uso, conservación y recuperación de los recursos que la nutren. Precisamente, este es uno de los circuitos que inyectaron energía a muchos campesinos en su movilización por la defensa del medio ambiente, como se puede apreciar en el relato de Benigno Loásiga de la comunidad Manceras:

En primer lugar, yo tengo muchos años de cuidar el bosque en mi propiedad. He tenido capacitaciones y orientaciones de parte de un organismo que se llama ADDAC. Hace mucho tiempo nos han enseñado a cuidar el medio ambiente, a cuidar el agua, los bosques y cuidar la tierra, no quemarla. Yo me puse a cuidar los bosques debido a un intercambio de experiencia en Guatemala [...]. Yo decía, que si fuera posible, daría mi vida por el medio ambiente, yo la daría con todo gusto. Por eso me llamó la atención, a cuidar, a conservar, y lo cuido mientras viva. Ese bosque no se va a tumbar (Benigno Loáisiga, comunicación personal, 30 de noviembre del 2015).

En este sentido, el ecologismo campesino en Rancho Grande tiene un espesor fértil en el proceso de apropiación de buenas prácticas productivas según el enfoque de agricultura sostenible. Las raíces de este modelo agroecológico en Matagalpa se remontan a una iniciativa entre artistas y agrónomos, quienes en 1989 deciden impulsar un "movimiento de contrapeso al modelo químico de agricultura y en búsqueda de alternativas culturales y productivas al modelo de modernización agrícola" (ADDAC y PROCASUR, 2013: 5). Este proceso de cambio dio origen y se fue desarrollando a través de dos expresiones: el Movimiento de Animación Cultural Rural (MACRU) y la Asociación para la Diversificación y el Desarrollo Agrícola Comunal. Esta última ha generado, 
por más de una década, un trabajo estable, profundo y sistemático en Rancho Grande, con lo cual se promueve la agricultura orgánica, la protección del medio ambiente, la organización campesina, el enfoque de género, la comercialización y el crédito alternativo. Algunos de los beneficiarios han sido cooperativas productoras de granos básicos, cacao, café, entre otros. Según Rodríguez y Hesse, el enfoque de agricultura sostenible:

No se limita en forma aislada a tratar el tema ecológico y ambiental, descuidando las estructuras que originan la pobreza y la marginación (...) sino que integra estrategias de desarrollo que movilizan la capacidad de negociación de conflictos, la incidencia en las políticas agrarias y la creación de condiciones de vida más justas y dignificantes (2000: 25).

Este ecologismo se genera a través de un proceso de toma de conciencia y decolonización de la naturaleza, y permite una manera distinta de relacionarse con ella e incluso asumir una perspectiva intergeneracional. Todo este mecanismo estuvo presente en la consolidación del movimiento social contra la minería en Rancho Grande.

Samaria Márquez Rizo, secretaria de Guardianes de Yaoska y una de las líderes más jóvenes de este movimiento, pone en entredicho el discurso de la civilización en el debate sobre el modelo extractivista y el ecologismo campesino:

Muchas veces nos decían que éramos ignorantes y fueron muchas las veces que nos dijeron que a nosotros lo que nos hacía falta era civilización, era el pan nuestro de todos los días. Pero nosotros en la radio muchas veces, dijimos que para amar la tierra no se necesita de civilización y que el campesino no necesita tanto la civilización para saber que la tierra es la que nos provee, tanto de los alimentos como de agua y tantos recursos (Samaria Márquez Rizo, comunicación personal, 30 octubre del 2015).

En estos discursos, pronunciados sobre todo por mujeres, se observa lo que Escobar (2010) denomina "una ontología relacional", la cual se expresa en esa relación afectiva y espiritual con la tierra -en tanto ser viviente, como madre y don sagrado-. Hay una feminización de la tierra asociada a su generosa fertilidad: "estudiando La Biblia, saco el valor que se le debe dar a la madre tierra de cuidarla, defenderla, porque dice que es como el vientre de una madre" (Elizabeth Chavarría, comunicación personal, 29 octubre del 2015).

Precisamente, desde la experiencia de fe y el principio de superviviencia del ecologismo de los pobres, el movimiento social en Rancho Grande se posiciona frente al extractivismo: "no me nace apoyar eso [la minería] porque no estoy a favor de la destrucción del medio ambiente. Entonces, lo que me motiva es que debo de amar la madre tierra, porque es el tesoro que Dios nos dejó a nosotros" (Elizabeth Chavarría comunicación personal, 29 octubre del 2015). Esta cosmovisión contrasta con la "ontología 
moderna occidental" que divorcia la cultura de la naturaleza, cosifica y se centra en el valor comercial de esta; lo cual es propio del extractivismo.

Actualmente, el extractivismo minero representa una de las formas más voraces de producción y de esparcimiento de capital con un alto poder de destrucción social y ambiental en los territorios de enclaves. En los últimos diez años, la región centroamericana se ha presentado como uno de los espacios con más significación en el llamado "nuevo modelo extractivista" (Zibechi, 2011). Se trata de la segunda fase del neoliberalismo que inició hace más de una década.

Con independencia de la orientación política-ideológica del partido en el poder, los gobiernos de la región han asumido el modelo extractivista como la ruta inmediata para atraer inversión extranjera directa o incrementar la captación de renta. Todo esto sin discutir la lógica de este desarrollo y además obviando los impactos socioambientales de muchas comunidades, como ha sido el caso de Rancho Grande. Por lo general, muchos movimientos sociales en América Latina no han logrado encontrar canales de diálogos efectivos con sus respectivos gobiernos, con el fin de propiciar un debate serio y profundo sobre los posibles modelos de desarrollo local, nacional e incluso regional (Composto y Navarro, 2014).

Otra característica de este modelo extractivista, es el hecho de que las conflictividades socioambientales -a nivel local, nacional y global- son resultado, diría Svampa (2016), de "la reproducción globalizada del capital, la nueva división internacional del trabajo, la desigualdad social" y sobre todo por "el desplazamiento geográfico de las fuentes de recursos y de los desechos" (181). Se trata de la relación del "capitalismo avanzado" con el tradicional, cuyo vínculo está marcado por la extracción y destrucción de recursos, bienes comunes y personas. Según Sassen (2015), en este capitalismo los recursos naturales de buena parte de los países del sur o de la periferia son más importantes que la gente que vive en estos territorios.

La implantación de esta dinámica de acumulación y despojo ha chocado con el crecimiento de comunidades en resistencias, ${ }^{36}$ las cuales han diversificado sus repertorios y frentes de luchas, como han sido los casos de la Mesa Nacional contra la Minería en El Salvador, Crucitas en Costa Rica, Cerro Colorado en Panamá y, en el caso más reciente y que atañe a este estudio, el de Rancho Grande en Nicaragua.

\section{El adversario: su genealogía de "violencia colonial"}

Machado (2014) señala que "la modernidad, es decir el capitalismo y el colonialismo propiamente moderno, nació de ese peculiar encantamiento provocado por el oro sobre las miradas, las 'almas' y los 'corazones' de los 'conquistadores, es decir: de la codicia como habitus dominante" (63). En este sentido, la minería moderna tiene su genealogía en la "violencia colonial". En las últimas décadas, el incremento de la demanda de los minerales y su progresivo agotamiento se convirtió en uno de los 
factores que intensifica los niveles de violencia estructural. Además, ha obligado a muchas empresas, con la complicidad de los gobiernos, a desarrollar mecanismos fraudulentos y tecnologías de penetración sociocultural cada vez más sofisticados, a fin de garantizar la licencia social necesaria. Este punto es relevante para las transnacionales mineras y sus socios porque saben que toda intervención en un determinado territorio genera afectaciones o daños en los medios de vida, formas culturales y políticas a través de las cuales se garantiza la reproducción social de determinadas grupos humanos o poblaciones (Machado, 2014).

En el caso que interesa en este estudio, uno de los primeros pasos para establecer la minería en Rancho Grande fue la creación de la alianza Estado-empresa minera, pues esta conexión permitió garantizar estrechas y efectivas relaciones con los gobiernos a distintas escalas. Según una líder y miembro del Movimiento Comunal de Matagalpa,

El gobierno fue cómplice de todo lo que la empresa minera allá hizo y cómplice porque dio lugar a que se manipularan los mismos proyectos del gobierno, que si el zinc ${ }^{37}$ que iban a dar, el que lo entregaba no era el secretario político, sino un representante de la B2GOLD. Hace como 2 años, [llega] una brigada de médicos del ejército allá en la zona y quien los presentó no fue el ejército como ejército, como una brigada que fuera a dar servicios de Salud. Sino que quien los presentó fue la B2GOLD en la propaganda que ellos hacian. (María Auxiliadora, comunicación personal, 14 de noviembre del 2015).

Ligado a la anterior, se desarrollaron políticas de imagen a través de las tecnologías de mercadeo social-corporativo que propiciaron el proselitismo minero. Por ejemplo, se repartieron gorras con logos de la empresa B2Gold y camisetas con alusión a la responsabilidad social empresarial. Concretamente, los funcionarios de dicha empresa hacían propaganda del vivero forestal que habían financiado. Estos materiales fueron distribuidos entre docentes de las escuelas, personal de salud, etc. Además, B2Gold pagó la divulgación de mensajes radiofónicos sobre las bondades de la minería verde y su contribución a la generación de empleos y desarrollo económico en el municipio y en el país. A su vez, funcionarios de la empresa minera les prometieron bonanza y prosperidad a los propietarios de comedores, hostales ubicados en el casco urbano del municipio de Rancho Grande, dado que la actividad minera traería trabajadores y técnicos de otras partes, quienes requerirían de sus servicios y del consumo de ciertos productos. Incluso, les ofrecieron apoyo para mejorar sus capacidades instaladas y la calidad del servicio que ofrecerían. En consecuencia, algunos de estos propietarios, una minoría sin organización, fueron quienes se manifestaron a favor de esta actividad.

En el contexto de pobreza u orfandad por parte de Estado, como sucedía en Rancho Grande, la competencia por el reparto de nuevas oportunidades económicas 
se convirtió en un asunto de micro y macropolítica. Concretamente, B2Gold recurrió al tema de los empleos, las regalías e incluso la compra de tierra a través de testaferros. En el caso de la generación de empleos, uno de los líderes del movimiento Guardianes de Yoaska comentó que

Las estrategias de ellos no cuajaron, porque le daban trabajo a una persona un mes. Después salía ese y entraba otro, pero esa persona que salió quedaba en planilla como si estuviera trabajando, ellos tenían 80 personas trabajando ahí en la mina. Pero en planilla tenían como 200-300 porque iban sacando [...] pero había veces que decían "tenemos hasta 400 empleados (Ernesto Montenegro, comunicación personal, 21 de noviembre del 2015).

De forma similar, en el caso de las regalías, María Auxiliadora, una de las entrevistadas advirtió que en la minería era costumbre "comprar" la conciencia de las personas del lugar, con el fin de obtener el apoyo de ese grupo. Por su parte, sobre las compras de las tierras, los pobladores de Rancho Grande plantean que esta fue una de las líneas de acción de la empresa minera:

La estrategia sucia de la empresa es ir a Yaoska, te compran una finquita ahí, estás ahí como que querés trabajar la tierra y después nosotros te la compramos, así vinieron muchos a comprar una finquita, con engaños le compraban al finquero y después les vendían [a la empresa minera, para ello] ocupan de testaferro (Ernesto Montenegro, comunicación personal, 21 de noviembre del 2015).

Ahora bien, con respecto a los medios de comunicación, la alianza Estado-empresa minera, en el marco de la campaña social, hizo un despliegue y saturación de los distintos medios de comunicación locales, pues intentaron agresivamente persuadir y crear una opinión pública favorable a la minería. Como consecuencia se cerró el espacio a otras voces divergentes y a la cobertura mediática de las acciones y demandas del movimiento social.

Uno de las acciones de las empresas extractivas más recurrentes en los conflictos socioambientales, en alianza con las instituciones públicas, son las acciones violentas. Dávalos (2011) y Figueroa-Ibarra (2011) coinciden en que la violencia, la criminalización social y el uso del miedo son mecanismos de dominación política, para resolver este tipo de conflictos.

Detrás de cada contienda socioambiental, se da una cruenta batalla entre intereses corporativos o privados versus el movimiento social que defiende "el bienestar de los ciudadanos convertidos en voceros, defensores y militantes de la naturaleza" (Toledo, Garrido y Barrera-Basols, 2013). No es de extrañar que el último informe de Global Witness (2015) inicie con las siguientes palabras: "Activistas del mundo entero están muriendo en cantidades nunca vistas por intentar defender su tierra y proteger 
el medio ambiente frente al aumento de la competencia por los recursos naturales" (4). Basta ver el reciente asesinato de Berta Cáceres ${ }^{38}$ en Honduras.

Excurso 2

VIOLENCIA HACIA DEFENSORES AMBIENTALES

En 2014 observamos 116 casos de asesinatos de defensores de la tierra y el medio ambiente en 17 países: una media de más de dos víctimas mortales a la semana, lo que representa casi el doble del número de periodistas asesinados durante el mismo año. Aproximadamente tres cuartas partes de estas muertes tuvieron lugar en Centroamérica y Sudamérica y el sureste asiático fue la segunda región más afectada. Una vez más, el país más perjudicado es Brasil, seguido de Colombia, Filipinas y Honduras.

Los asesinatos son el caso más extremo de todos los riesgos a los que se enfrentan los defensores del medio ambiente y la tierra, que incluyen amenazas de muerte y violencia física, criminalización y restricción de las libertades. Muchos de estos defensores viven en comunidades remotas y pobres y cuentan con un acceso reducido a comunicaciones, medios de comunicación y acceso a la justicia, lo que los coloca en una situación de mayor riesgo". Una de las primeras causas de asesinatos es provocada por la fiebre del oro y los recursos que se requieren para su extracción.

Fuente: Global Witness, 2014: 4.

En el caso de Rancho Grande, como lo han manifestado algunos de los líderes entrevistados, el movimiento Guardianes de Yaoska, miembros de las comunidades, el Grupo Estratégico e incluso la Iglesia fueron sometidos a distintas formas de violencia, desde las más blandas a las más duras. Por ejemplo, María Auxiliadora del Movimiento Comunal de Matagalpa fue procesada judicialmente en un caso arbitrario por haber hecho una pinta ${ }^{39}$ en el muro de la oficina de B2Gold en Yaoska, las audiencias programadas fueron reiteradamente suspendidas, hasta que al final se cerró con una conciliación económica, cuyos fondos fueron recolectados por la gente que la acompañó. Esta misma lideresa tenía conocimiento de otros tipos de acciones más violenta que constituían claras y graves violaciones a los derechos humanos, sufridas por algunas familias campesinas:

Hubo muchas intimidaciones. Yo tenía la oportunidad de hablar en cualquier momento con gente de allá, donde llegaban a sus casas encapuchados y les preguntaban que si tenían armas, que si tenian drogas. Algunos de ellos estuvieron detenidos un mes, producto de una arma que le encontraron, pero que él la había comprado legalmente sin haber cometido ningún delito. Además, a este señor le robaron 10 mil córdobas y a su mujer la manosearon, la obligaron a desvestirse, porque era ella la que escondía las cosas que ellos buscaban [...]. Otros que fueron llevados no a la policía, sino que al plantel de la B2GOLD, para ser interrogados, también ellos pueden dar fe de esa situación. Y lo otro, es que les mandaban personas, [para] convencerlos 
de que lo mejor que podian hacer era estar a favor de la mineria y no continuar en contra de ellos, porque esto significaba que iban a tomar represalias contra ellos (María Auxiliadora, comunicación personal, 14 de noviembre del 2015).

Las acciones de hostilidad y amenaza eran temas que, aunque no dejaban de preocupar a los líderes de la Iglesia, no tuvieron el efecto esperado en ellos y en sus agentes de pastoral, según lo hizo saber el párroco de Rancho Grande, el padre Paulo Espinoza:

Siempre salen los rumores de lo que están planificando, a mí no me da miedo. Últimamente la amenaza de muerte para nosotros los sacerdotes, y aquí estamos, eso da más valor a uno. La amenaza a muchos de los delegados de la palabra, de que la policía los ha detenido en los cruces de camino cuando salen de sus comunidades [para] ver que andan sus documentos en orden, se les nota el estilo típico de ellos, de quererles hacer algo. ;Ah, ustedes trabajan con el padre de ahí! (Paulo Espinoza, comunicación personal, 21 de noviembre del 2015).

La instrumentalización de la violencia fue otra de las estrategias fallidas en Rancho Grande que no logró erosionar y desarticular el movimiento social contra la minería. Sin embargo, se torna importante reconocer otros procesos nocivos, como la mineralización social (Machado, 2014). Esta se entiende como la domesticación y

... acostumbramiento, aceptación y adaptación a [...] formas de violencia y de destructividad (social y ambiental) a fin de volver "tolerable" la vida en un entorno minero. La dinámica de las "compensaciones" funciona como las anestesias sociales que hacen soportable el dolor de la amputación territorial (Machado, 2014: 62).

Esta estrategia fue ensayada infructuosamente con el obispo de la Diócesis de Matagalpa, cuando

En un primer momento quisieron convencernos de la factibilidad y de la importancia de la minería. En un segundo momento se quisieron acercar a nosotros con intenciones nada sublimes, de irrespeto a nuestros criterios y a nuestras posturas. Un tercer momento yo diría que coacción pues querían presionarnos desde diversos ángulos, haciendo todo un lobby con altas personalidades del mundo eclesiástico, político, económico (Monseñor Rolando Álvarez, comunicación personal, 28 de noviembre del 2015).

\section{El efecto de la cigarra}

Ante la naturaleza de este adversario, el movimiento social desarrolló estrategias diversas que lograron calar en la dinámica de la contienda política. Estas acciones 
más significativas se dieron a lo largo del año 2015, cuando las estrategias de penetración social de la Alianza Estado-empresa minera se hicieron más notorias.

La empresa minera empezó a hacer proselitismo en los centros de salud, en las actividades de la alcaldía y hasta en las escuelas del municipio. Esta acción fue vista como una oportunidad del movimiento social ranchograndeño para actuar decididamente. En las escuelas, la empresa minera dio charlas al estudiantado sobre los beneficios de la minería. Ante esta situación, los padres y madres de familia decidieron hacer un boicot escolar: ningún niño, niña o joven iría a las escuelas hasta que se dejaran de impartir esas charlas. Así relata Carlos Siles, uno de los líderes del movimiento:

Hay comunidades en las que pasaron tres meses cerradas las escuelas, un 90 por ciento del municipio cerró sus escuelas, porque no llegaban los niños. Los padres no los mandaban por la amenaza. Estamos claros de que la empresa es alguien con dinero y a un niño fácilmente te lo engañan. Ellos llegaron a una escuela a hacer la capacitación, entonces a los niños les decían: "un refrigerio" y les comenzaban a preguntar "Hijito ¿quién es tu papá? ¿Quién es tu mamá? ¿Cuántos viven en tu casa?". Entonces después llegaban allá. En la comunidad toda esta gente está con nosotros. Entonces de ahí surgió el paro escolar y fue algo exitoso, porque con ese paro escolar tuvo que venir el Ministro de Educación (Carlos Siles, comunicación personal, 21 de octubre del 2015).

De esta forma, y a partir del paro escolar, el movimiento social empezó a hacerse notar más allá de las fronteras del municipio. A pesar del costo social y humano que representó el boicot escolar para las familias campesinas, esta acción es considerada por el movimiento social como una de las estrategias de presión más eficaces y de mayor impacto en la contienda frente a la alianza Estado-empresa minera. Concretamente, uno de los efectos que suscitó el paro escolar iniciado el 13 de julio del 2014 fue la visita de funcionarios de rango ministerial y autoridades del gobierno local en Rancho Grande. A esta reunión asistieron María Isabel González, alcaldesa de Rancho Grande; Lorena Lanzas, viceministra del Ministerio de Energía y Minas (MEM); Juanita Argeñal, titular del Ministerio de Medio Ambiente y Recursos Naturales (MARENA); Miriam Raudez, ministra de Educación y Deporte (MINED) y Zadrach Zeledón, alcalde de Matagalpa. En este encuentro las autoridades públicas intentaron persuadir a los líderes de Guardianes de Yaoska para que suspendieran el paro escolar y apoyaran el desarrollo de la actividad minera en el municipio. Sin embargo, resultó ser infructuosa porque ni siquiera lograron un ejercicio de consulta pública que legitimara socialmente la concesión en el cerro Pavón. Por el contario, las palabras de la viceministra del MEM despertaron mayor preocupación, pues la disposición del gobierno de Nicaragua era garantizar que toda inversión extranjera en exploración minera tendría las garantías de usufructuar la concesión para recuperar su inversión y obtener ganancias en el país (Sosa, 2015). 
Además, la alianza, conformada por las Iglesias católica y evangélica, una población descontenta y violentada ${ }^{40}$ y la ONG que les apoyaba, convocó para los primeros días de octubre del 2015 una multitudinaria marcha contra la minería, denominada de manera estratégica por el movimiento como "Peregrinación por la Vida". Aunque no se dispone de un registro preciso del número de participantes, según los organizadores aproximadamente asistieron más de diez mil personas a esta actividad y manifestaron su sentir a favor de la vida y su rotundo rechazo a la minería metálica. Este evento fue interpretado como un plebiscito político, según lo manifiesta Monseñor Sacasa: "Si el gobierno se decidió a apoyar a la mina, el pueblo se decidió a rechazar la mina; entonces estamos haciendo un referéndum político también" (Monseñor Edgard Sacasa, comunicación personal, 28 de octubre del 2015).

Las imágenes de la peregrinación y las voces del movimiento social se escucharon en Managua y en muchos medios de comunicación nacional, las cuales fueron vistas como una amenaza a otros intereses del Estado. Una semana después, el 12 de octubre del 2015, el Gobierno de Nicaragua declaró inviable la actividad minera en Rancho Grande. Los actores contendientes, reunidos en torno al movimiento social Guardianes de Yaoska, lograron alcanzar sus objetivos, es decir, paralizaron y evitaron el desarrollo de la explotación minera en su municipio, a pesar de que la alianza Estado-empresa minera había sufrido un conflicto social prolongado, trastocado por múltiples expresiones de violencia.

Ahora bien, hay una serie de elementos, ya mencionados, que abonaron a la resiliencia y empoderamiento del movimiento social, como el proceso de información, formación, sensibilización, fortalecimiento organizativo y movilización en torno a la amenaza de la extracción minera. Sumado a ello, la conciencia de que nadie además de ellos iba a defender y garantizar sus derechos socioambientales y de la madre tierra se convirtió en un detonante clave, según lo comenta uno de sus fundadores:

Movimiento social somos nosotros. Nosotros somos un movimiento social que nacimos para proteger a Rancho Grande, para proteger nuestro medio ambiente, para luchar para que se nos escuche, porque aqui en Rancho Grande, últimamente no tenemos una persona dentro del gobierno o la Alcaldía que esté pendiente de lo que está pasando en las comunidades (Carlos Siles, comunicación personal, 21 de noviembre del 2015).

La madurez y el despojo de las diferencias o intereses particulares, más allá de las barreras religiosas e ideológicas, le imprimió un nivel de cohesión, empoderamiento, legitimidad y representatividad al movimiento social frente a sus comunidades y aliados, y, en cierta manera, reconocimiento por parte sus adversarios. En esta línea un líder comenta: "[Le] llegamos a demostrar al Gobierno o al mundo que se puede luchar y ganar. ¿Cómo se logra esto? Como ya dije, unidos, despojándonos de partidos, unidos todos, 
liberales, sandinistas, evangélicos, católicos por una solo causa y la no-violencia" (Carlos Siles, comunicación personal, 21 de noviembre del 2015).

La integración de líderes de los distintos partidos políticos no fue un ejercicio meramente espontáneo, sino que se convirtió en un proceso de maduración política para tomar distancia de ciertas estructuras, así como para refutar algunos cuestionamientos o descalificaciones por parte de algunos miembros de la Alianza Estadoempresa minera dirigidas al movimiento social. En algunos casos los líderes iniciaron esta ruta con un proceso de ruptura con sus partidos políticos:

Pertenezco al Frente Sandinista, he sido militante del Frente Sandinista desde que tengo uso de razón, mi familia y todo, pero desde ese momento que aqui se estaban dando todas esas cosas, yo no volví a asistir a una reunión ni del partido ni de la Alcaldía. Es más, aquí en mi casa se hacian reuniones, les llamaban escuelas de campo del gobierno. Yo les dije: no quiero más que vuelvan aqui, hasta que esto se arregle (Ernesto Montenegro, comunicación personal, 21 de noviembre del 2015).

A partir de estas reflexiones se evidencia que este compromiso por la defensa del medio ambiente no solo implica pragmáticamente el principio de supervivencia, sino que suscita un redimensionamiento de los valores y la ética que trasciende los encasillamientos ideológicos y partidarios. Como advierte Martínez Allier (2001), los conflictos económico-ecológicos "son disputas o diálogos multicriteriales (...) y revelan un enfrentamiento de valores inconmensurables" (127).

Esta discusión ética del movimiento social no supone para algunos líderes y miembros del FSLN renunciar a su ideología política, sino reivindicar su sentido auténtico y radical, como señala Luz Marina Zeledón, quien fue secretaria política de dicho partido en la comunidad ranchograndeña Pájaro San Juan.

Uno es lo que es, pero tiene que ser sandinista con dignidad y no interesado al dinero. Porque uno trabaja por la comunidad, por los jóvenes, por los adultos, por todos los que habitan en la comunidad, y luchar para sacar a la comunidad adelante. Pero no para tener una comunidad destruida (comunicación personal, 30 de octubre del 2015).

Asimismo, la estrategia comunicativa fue parte del repertorio de acciones aprovechadas por el movimiento social de múltiples maneras. La difusión de ideas a través de medios de comunicación alternativos fue efectiva, así lo señala un miembro del GEM: "para mí estos medios de comunicación aunque eran pocos, también han tenido cohesión y han dado voces a otros discursos" (Juan Herrera, comunicación personal, 14 de octubre del 2015).

Una mirada desde las organizaciones que apoyaron el movimiento social reconoce la naturaleza del liderazgo propio, la autonomía, la identidad y el arraigo territorial. 
En esta línea, el liderazgo de la Iglesia católica matagalpina aprecia el valor y el coraje que mostró el movimiento social frente a las amenazas y adversidades, lo cual contrasta con la mirada de los partidos políticos que impulsan y apoyan abiertamente la minería (el FSLN), y de otros que no asumieron posiciones frente al conflicto (el PLC y el PLI). Como consecuencia de este desgaste de los partidos políticos, los ranchograndeños se han movilizados más allá de las estructuras partidarias. Tal como lo indica el vicario de la Diócesis de Matagalpa:

(...) hoy creemos que el pueblo [de Rancho Grande] es capaz de hacer, lo que los partidos politicos no son capaces de hacer, y estamos equivocados cuando decimos que la gente tiene miedo, no sé si lo tiene o no, pero la gente es capaz de moverse y que al movilizarse mueven la nación (Monseñor Sacasa, comunicación personal, 28 de noviembre del 2015)

Inclusive, las mismas amenazas se convirtieron en oportunidades para fortalecer la cohesión y la solidaridad del campesinado. De esta forma, más allá de provocarles miedo, sirvió para fortalecer su organización, para unirse más como grupo y crear ideales más coherentes entre católicos y evangélicos, sandinistas y liberales. "Yo creo que en ese sentido los movimientos sociales cuando ven realmente su causa, cuando ven las injusticias y cuando se ven amenazados de actos como este, es una reacción muy acertada, muy unida, muy coherente" (María Auxiliadora, comunicación personal, 14 de noviembre del 2015).

Se puede afirmar que el proceso de lucha del movimiento social demostró una enorme capacidad de recrearse e incluso de concebir otras formas de hacer política contrarias al verticalismo y al abuso de poder. En esta línea, uno de los líderes de Yaoska manifiesta en las siguientes declaraciones, la ruptura con esta cultura política en el ámbito local:

Ellos creían que [...] la mina iba porque iba, costara lo que costara; porque era una orden de arriba, allá lo dijo el comandante y aquí se acabó todo. [Nosotros siempre decíamos que] allá arriba podian decir una cosa, pero en Rancho Grande decimos otra, y Rancho Grande es el que va a responder (Ernesto Montenegro, comunicación personal, 21 de noviembre de 2015).

Otra lectura sobre este proceso de maduración política, es la redignificación de los mismos actores comprometidos en su lucha común, según lo expresa el Obispo de Matagalpa, Rolando Álvarez:

... nace del reconocimiento de su dignidad como persona, de tal manera que también hay una historia y una tradición que se ha venido clarificando y consolidando cada vez más de lucha común. Más allá de los colores políticos, de las tendencias ideológicas y de las pertenencias religiosas (comunicación personal, 28 de noviembre del 2015). 
Una vez que el Gobierno dio marcha atrás a la concesión minera del Cerro Pavón, el movimiento social se ha mantenido atento ante cualquier problemática que afecte su relación con el medio ambiente y las bases de su estrategia de vida. Al mismo tiempo, luego de haber hecho efectiva su reivindicación, consolidó una identidad y un proyecto en común como es la defensa por el medio ambiente; lucha que se volvió un referente inédito contra el extractivismo en todas sus expresiones. Así lo ratifica el vicario de la Diócesis de Matagalpa:

Rancho Grande también se ha convertido en una luz para mucha gente, así como a nosotros nos dio luz el Canal, el Tule, ahora esto ilumina a muchas otras comunidades, yo creo que lo van a tener que pensar bien a la hora de otro fenómeno que se pueda dar. (...) Está ya, en la conciencia popular que no se puede ir contra la tierra, contra la naturaleza, contra la creación y eso es muy espeso (comunicación personal, Monseñor Sacasa, 28 de octubre del 2015).

En síntesis, la acción colectiva del movimiento Guardianes de Yaoska, en el marco de la contienda política por los recursos, ha representado un quiebre para los discursos y prácticas políticas dominantes, y la emergencia de nuevas formas de hacer política. En este sentido, su capacidad de construir territorio desde perspectiva del ecologismo campesino, que a su vez se ha nutrido de cierta tradición ecológica del cristianismo y de muchos años de apropiación de un modelo de agricultura sostenible.

\section{Conclusión}

La dinámica de la contienda política en el municipio de Rancho Grande no puede entenderse fuera de su contexto histórico, socioambiental y político. La movilización social en contra de la minería fue un proceso sostenido de aproximadamente una década, cuyas primeras acciones, realizadas por el párroco Teodoro Custer y un pequeño grupo de líderes de la Iglesia católica, estaban orientadas a sensibilizar y alertar de los peligros y efectos de la actividad minera en las comunidades. Progresivamente, se fueron sumando a dicho proceso otras organizaciones que brindaban asistencia técnica a la producción agropecuaria desde el enfoque de la agricultura sostenible. Todo esto abonó al reforzamiento de una visión del desarrollo sostenible acorde con el tema de la justicia social, viabilidad económica y equilibrio ecológico.

A partir de esto, se puede afirmar que en Rancho Grande entraron en contradicción, por un lado, el proyecto extractivista, impulsado por la alianza B2Gold y el Gobierno de Nicaragua, y por otro, el modelo productivo de agricultura sostenible, del cual se apropiaron los campesinos y productores de dicho municipio. Para estos últimos, la contradicción no solo se restringía a un problema del choque entre una actividad económica con el manejo de los recursos naturales y su impacto, sino a la naturaleza irregular y poco transparente del proceso de concesión minera. Asimismo, 
a las estrategias de penetración social que chocaban con el ejercicio de ciudadanía y el sentido de justicia social desarrollado progresivamente por el movimiento Guardianes de Yaoska.

Otro elemento importante, relacionado con el ecologismo de los pobres y el empoderamiento del movimiento Guardianes de Yaoska, fue la tradición ecológica de la Iglesia católica; así como su opción pastoral y política de acompañar dicho movimiento y hacer eco de sus reivindicaciones a los niveles más altos de la política del país. Estas certificaciones, en cuanto estructuras de oportunidades, fueron aprovechadas por el movimiento social, en términos de legitimación y empoderamiento; especialmente porque vinieron a reforzar la dimensión religiosa del ecologismo de los campesinos y líderes de Rancho Grande; elemento que les dotó de mayor resiliencia ante las adversidades.

La opción por la vida en defensa del medio ambiente fue un elemento movilizador que logró articular con solidez a los distintos actores ranchograndeños, incluso trascendiendo las ideologías políticas y las afiliaciones religiosas. Además de articular y cohesionar el tejido social, que mayoritariamente se oponía a la minería, las comunidades asumieron en su discurso que el problema de fondo era la disputa y hegemonía de un modelo de desarrollo colonizador y depredador, frente a un modelo de desarrollo sostenible. Así, la acción colectiva no violenta del movimiento social demuestra, que es posible pensar lo medioambiental más allá de un modelo económico extractivista.

De la experiencia de Rancho Grande se rescata que las estrategias del adversario (alianza Estado-empresa minera) fueron esfuerzos infructuosos en términos de resultados y eficacia, entre estos se destaca: 1) la campaña social (legitimidad a través de la persuasión de la opinión pública), 2) la compra de tierras de manera indirecta a través de testaferros, 3) las estrategias de manipulación en torno a mitos como el progreso minero, la generación de empleos; 4) el aprovechamiento del vacío institucional en el territorio a través de falsas regalías (financiadas por programas del Estado) y "mejoramiento" de la condición de vida los pobladores por medio del barniz de responsabilidad social empresarial; 5) las acciones violentas de distintos niveles o envergaduras (amenazas, miedo político, actos legales-enjuiciamiento y privación de libertad que vulneraron los derechos humanos. Además, para contrarrestar estos repertorios fueron determinantes el nivel de conciencia, empoderamiento y cohesión del movimiento, así como las habilidades para aprovechar las oportunidades y fortalezas de sus aliados estratégicos.

Finalmente, se destaca que el movimiento Guardianes de Yaoska logró hacer efectiva su demanda, de manera pacífica en un contexto adverso, en el que, por lo general, los conflictos suelen escalar en dinámicas de violencia colectiva. Además de este precedente, desde la perspectiva de la no-violencia, representa la necesidad discutir consuentudinariamente las apuestas estratégicas en torno a los modelos de desarrollo y su viabilidad en términos socioambientales. 


\section{Notas}

1 Se agradece el trabajo de los coautores del diseño del proyecto de investigación: Douglas Ernesto Castro, Néstor López Irías y Claudia Lönze. Colaboración en la redacción de resumen o abstract en inglés Sergio Miguel Cabrales. Revisión y corrección del texto y bibliografía: Douglas Ernesto Castro, Guillermo Pérez Molina, Sergio Miguel Cabrales y Néstor López. Se agradece las transcripciones de las entrevistas a Cristiana María Huerta.

El concepto de los minerales estratégicos hace referencia a minerales no combustibles que son indispensables para el desarrollo de industrias y sectores tecnológicos importantes en la economía de una nación. Los informes elaborados anualmente por el Departamento del Interior de los Estados Unidos, advierten que este país se caracteriza por su alta dependencia de importaciones y abastecimiento de este tipo de minerales para su economía (Bruckmann, 2011: 29-36).

Cabe destacar la valiosa labor de acompañamiento a las comunidades afectadas por la violencia política durante los años de represión y conflicto armado, por parte de religiosas y sacerdotes católicos como Rogelio Poncel y Antonio Velázquez, en el departamento de Morazán; Ángel Arnaíz y Pedro Decler, en Morazán y Usulután; Nicolás Alvarenga sj, Miguel Vásquez sj, Manolo Maqueira sj, John de Cortina sj, Monseñor Arturo Rivera y Damas, en el norte de departamento de Chalatenango. Indudablemente, el legado del mártir y obispo Óscar Arnulfo Romero Galdámez representó una reserva moral y espiritual para la resistencia y la lucha de muchas comunidades en contra de la represión, el terrorismo de estado cometido por el Gobierno de El Salvador durante el conflicto armado.

Como por ejemplo la incompatibilidad entre la acumulación de capital y la sostenibilidad de la vida; el reforzamiento de las relaciones de poder desiguales y jerárquicas entre hombres y mujeres, etc.

Casos de Guatemala, El Salvador, Costa Rica y Nicaragua.

Se asume en el estudio como ecologismo de los pobres, la defensa del medio ambiente que hacen los pobres -indígenas, campesinos, comunidades marginales- cuando su subsistencia y estrategias de vida, que depende de la conservación de éste, se ven amenazadas o vulneradas por dinámicas extractivas o depredadoras.

En diciembre del 2015 la Asamblea Nacional aprobó la Ley de Seguridad Soberana de la República de Nicaragua, la que considera como amenaza "cualquier otro acto o actividad ilícita, o factor natural que atente contra el desarrollo integral de las personas, la familia y la comunidad" (\# 13, Art. 8, Ley 919, La Gaceta, 2015). Este tipo de legislación abre la posibilidad de considerar la protesta socioambiental como acto ilícito en contra de desarrollo.

El neoextractivismo se corresponde con el reordenamiento territorial en función de la mercantilización de los territorios y su integración a las dinámicas de acumulación financiera del capitalismo global (Gudynas, 2009; Luxemburgo, 1978). Esta tendencia del gobierno de Nicaragua, se puede constatar con la expansión de cultivos intensivos como la palma africana, caña de azúcar ampliamente estudiado por Baumeister (2013) y en el turismo por Cañada (2010, 2013), entre otros. ${ }^{*}$ ¿Es exclusiva de Nicaragua? Identificarla como una tendencia que ha caracterizado varios modelos de desarrollo contribuiría a contextualizar y advertir sobre los potenciales resultados. 
Ejemplos de estas situaciones han sido la detención 12 productores y productoras de las zonas de Rancho Grande y Waslala (agosto 2014), y recientemente, ante las protestas y hechos violentos, fueron detenidos e imputados tres líderes sindicalistas de la mina El Limón y otra veintena de trabajadores y habitantes de este distrito minero bajo la figura de crimen organizado, homicidio, daños agravados y violación (octubre de 2015).

Es el titular de la entrevista que la periodista Gisella Canales Ewest realizó a Pablo Venturo, gerente general de B2Gold, publicada en el diario La Prensa, con fecha 26 de febrero del 2014. Ver: http://www.laprensa.com.ni/2014/02/26/economia/184194-nicaragua-es-un-pais-minero

PRONicaragua fue reconocida por el Banco Mundial como la mejor del mundo en su desempeño de promoción de inversiones extranjera. Esta distinción se hizo en el marco del tercer Foro Mundial de Inversiones 2012.

Para esl 2016, se tiene previsto la realización del II Congreso Internacional de Minería, que se llevará a cabo el 16 y 17 de agosto en la ciudad de Managua. El eslogan para este evento es "Minería para todos".

Ley 334 para la Promoción de la Inversión Extranjera, la suscripción del Gobierno de Nicaragua a los Acuerdos Bilaterales de Promoción y Protección Recíproca de Inversiones, Ley Especial de Exploración y Explotación de Minas (Ley 387), Decreto N. ${ }^{\circ}$ 119-2001. En términos fiscales, la exención de impuestos para los insumos, maquinaria y otros efectos se aplica siempre y cuando estén directamente relacionadas con las actividades de la concesión minera.

Según declaraciones de Jurguen Guevara del Centro Humboldt a un medio informativo ( $\mathrm{La}$ Prensa, 22 de febrero de 2016).

Los encuentros se realizaban en la delegación de la policía en Juigalpa, con el agravante de que los líderes comunitarios eran fotografiados y se les obligaba a firmar un documento de compromisos de voluntad de llegar a acuerdos, cada vez que asistían a una reunión.

En la 153 período de sesiones de la CIDH, audiencia temática sobre el uso indebido del derecho penal para criminalizar a defensoras y defensores de derechos humanos.

Mónica Bruckmann, Joan Martínez Alier, Tania Sosa y Andrew McKenly.

Asociación por el desarrollo y la diversificación agrícola comunal (ADDAC), Asociación para el Desarrollo Integral Comunitario (ADIC), Movimiento Comunal de Matagalpa, CIBACTA, Radio Voz y el CENIDH-Sede de Matagalpa.

Por ejemplo, la cooperativa de Ríos de Agua Viva está conformada por 34 comunidades y 311 socios que promueven la agricultura orgánica, la protección del medio ambiente y el enfoque de género (Sosa, 2015).

Según datos de ADDAC, la producción de cacao en el 2013 fue de aproximadamente 10 quintales en baba (granos recubiertos de mucílago) (Sosa, 2015).

El último CENSO (2015) aún no se publica y el CENSO Agropecuario 2011 no tiene el nivel de desagregación que permita observar la superficie de las explotaciones agropecuarias.

Según las estadísticas sobre indicadores de pobreza muestran que la pobreza se han reducido estas no tienen representatividad municipal, por tanto no se pudieron utilizar para este estudio, lo que obligó a emplear estadísticas menos actualizadas. 
BOSAWAS; Reserva de Biósfera declara por la UNESCO en el año 1997.

Según este decreto, 76-2006, el mecanismo de gestión ambiental que establece un proceso compuesto de actos administrativos que incluye la preparación de estudios, celebración de consultas públicas y que concluyen con la autorización o denegación de parte de la autoridad competente, nacional, regional o territorial.

Salvo en el período de la Revolución sandinista cuando se nacionalizaron las empresas y los distritos mineros (Gutiérrez, 2015).

Un ejemplo dramático ha sido la situación del municipio de Bonanza, que a pesar de la explotación minera de oro, por más de 100 años, el 40 por ciento de su población sigue viviendo en la absoluta pobreza (McKinley, 2013).

El padre Custer fue una de las primeras personas en advertir los riesgos de la actividad minera en el municipio de Rancho Grande.

Entre los líderes cabe mencionar a Ministros de la Eucaristía, delegados de la Palabra, catequistas.

Líder comunitario dela Iglesia católica queen representación del párrococelebra dominicalmente la liturgia de la palabra en su comunidad.

La expresión se refiere a que la gente ya no se le engaña fácilmente.

Monseñor Rolando Álvarez, ha sido uno de los líderes de la Conferencia Episcopal más beligerantes en la lucha contra el extractivismo en Nicaragua. Se graduó en filosofía en la Universidad Gregoriana y una maestría en Doctrina Social por la Universidad Pontificia de Salamanca.

El padre Édgar Sacasa es párroco de la Iglesia Nuestra Señora de la Concepción en el Municipio de San Isidro-Sébaco. Realizó estudios de teología en la Universidad Centroamericana José Simeón Cañas de El Salvador. Fue formado por importantes teólogos de la liberación como el padre Jon Sobrino, al igual que estudió la filosofía de la Realidad Histórica del jesuita mártir Ignacio Ellacuría. Conocedor del legado apostólico y espiritual del obispo Mártir Óscar Arnulfo Romero.

La expresión es una metáfora de una falacia.

Un cristianismo marcado por una doctrina social de la Iglesia inspirada por la Conferencia Latinoamericana de Medellín y Puebla, además de la teología de la liberación.

Basados en agroquímicos, monocultivos para la exportación, en fin, las distintas prácticas impulsadas por la "agricultura verde" después de la Segunda Guerra Mundial.

Hay otros conflictos en la región como el de la mina Marlin en San Miguel Ixtahuacán y Sipacapa y la Mina Félix en Izabal, La Puya en San Pedro Ayampuc en Guatemala. La mina El Corpus en Choluteca, San Andrés en Copán Honduras, etc.

En muchos programas sociales de corte asistencialista está la distribución de láminas de zinc a familias que se han identificado como pobres y vulnerables. 
Berta Cáceres, indígena de la etnia lenca, una de las defensoras más reconocidas de los derechos humanos, los pueblos indígenas y el medioambiente. Era una de las defensoras ambientales más amenazadas de Honduras. A pesar que la Comisión Interamericana de Derechos Humanos (CIDH) había dictado medidas cautelares para su protección, fue asesinada por hombres armados en su casa, en el departamento de Intibucá, al oeste de Tegucigalpa, la noche del miércoles 2 de marzo del 2016. Cáceres había ganado en 2015 el prestigioso Goldman Environmental Prize, por su larga y valiente trayectoria ambientalista. En 1993 fundó el Consejo Cívico de Organizaciones Indígenas y Populares de Honduras (COPINH), lideró la oposición al proyecto hidroeléctrico de Agua Zarca que afectaba varios ríos en el departamento de Intibucá.

Una pinta es un grafiti con un mensaje, en este caso era "No a la minería".

40 El descontento y la violencia acumulada hacen referencia a dos situaciones: una de carácter estructural, relacionada con los niveles de pobreza -explicado en el apartado del contexto-, y la coyuntural, la forma en cómo el gobierno local y nacional apoyaba abierta y de forma autoritaria un proyecto minero, que lejos de revertir la situación de pobreza, vendría a destruir el ecosistema y los medios de vida, a despojar de la tierras consideras de interés para dicho proyecto minero. En fin, a exasperar más el empobrecimiento de los habitantes de Rancho Grande.

\section{Bibliografía}

Asociación para la Diversificación y el Desarrollo Agrícola Comunal (ADDAC). Datos de Rancho Grande. Matagalpa, s. f. <http://www.addac.org.ni/paginas/rancho-grande/?m=14>.

ADDAC y PROCASUR. Estudio de caso: Metodología del Programa Jóvenes emprendedores de ADDAC en Pancasán, 2013. <http://juventudruralemprendedora.procasur.org/wpcontent/uploads/2014/01/ADDAC.pdf>.

Alfaro, Angélica; Guevara, Olivia y Sosa, Tania. Valoración de riesgos e impactos socio-ambientales de la Minería Metálica en Nicaragua, 2013-2015. Managua: Centro Humboldt, 2015

Arellano-Yanguas, Javier. "De predicar a escuchar: industrias extractivas comunidades e Iglesia en el Perú rural". Las Iglesias ante la violencia en América Latina. Los Derechos Humanos en el pasado y en el presente. Ed. Alexander Wilde. México: FLACSO de México y Center for Latin American \& Latino Studies, 2015. 323-350.

Azar, Edward. The Management of Protracted Social Conflict: Theory and Cases. Dartmouth: Aldershot, 1990.

Banco Central de Nicaragua. Anuario de Estadísticas Macroeconómicas (1960-2014): Sector Real, Empleo y Salarios, Sector Externo. Managua: Autor, 2015.

Baumeister, Eduardo. Concentración de tierras y seguridad alimentaria en Centroamérica. Roma: Coalición Internacional para el Acceso a la Tierra, 2013.

Bebbington, Anthony. "Elementos para una ecología política de los movimientos sociales y el desarrollo territorial en zonas mineras". Ed. Antohny Bebbington. Minería, movimientos sociales y respuestas campesinas. Lima: IEP, CEPES, 2007. 23-44.

Boff, Leornado. Grito de la Tierra, grito de los pobres. Hacia una ecología planetaria. México: Ediciones Dabar, 1996.

. La opción Tierra. La solución para la Tierra no cae del cielo. Santander: Editorial Sal Terrae, 2005. 
Bruckmann, Mónica. Recursos naturales y la geopolítica de la integración Sudamericana. Instituto de Altos Estudios Nacionales, Universidad de Postgrado del Estado, 2012.

Bunker, Sthephen. Underdeveloping the Amazon: Extraction, Unequal Exchange, and the Failure of the Modern State. EE. UU.: Univ. of Illinois Press, Urbana y Chicago, 1985.

Cañada, E. (Ed.). Turismo en Centroamérica, nuevo escenario de conflictividad. Managua: Fundación Luciérnaga, 2010.

. (Coord.). Turismo en Centroamérica. Un diagnóstico para el debate. Managua: Enlace, 2013.

Carvajal, Laura María; Cabnal, Lorena; Raules, Gabriela; Cuenca, Ángela; Aliaga, Carmen y Gatica, Sofía. Mujeres defendiendo el territorio: experiencia de participación en América Latina. Colombia: Fondo de Acción Urgente de América Latina, 2015.

Consejo Episcopal Latinoamericano (CELAM). V Conferencia General del Episcopado Latinoamericano y del Caribe. Aparecida: Autor, 2007.

Comisión Económica para América Latina y el Caribe (CEPAL). Recursos naturales: situación y tendencias para una agenda de desarrollo regional en América Latina y el Caribe. Santiago de Chile: Autor, 2013.

Composto, Claudia y Navarro, Mina Lorena. Claves de lectura para comprender el despojo y las luchas por los bienes comunes naturales en América Latina. México: Bajo Tierra Ediciones, 2014.

Dávalos, Pablo. "Las falacias del discurso extractivista", 2013. <http://lalineadefuego. info $>$.

Equipo Envío. Vivimos en un paraíso y lo vamos a defender entre toditos de la minería, 2014. <http:// www.envio.org.ni/articulo/4909>.

Escobar, A. "Hacia el pluriverso". VV. AA. Conversaciones ante la máquina para salir del consenso desarrollista. Buenos Aires: Tinta Limón, 2015. 1169-180.

Escobar, A. Sentipensar con la tierra. Nuevas lecturas sobre desarrollo, territorio y diferencia. Medellín: UNAULA, 2014.

Escobar, A. "América Latina en una encrucijada: ¿modernizaciones alternativas, postliberalismo o posdesarrollo?". Ed. Víctor Bretón. Saturno devora a sus hijos: Miradas críticas sobre el desarrollo y sus promesas. Barcelona: Icaria, 2010. 35-85.

Figueroa-Ibarra, Carlos Figueroa. El Recurso del miedo. Estado y terror en Guatemala, Instituto de Ciencias Sociales y Humanidades "Alfonso Vélez Pliego". Guatemala: BUAP / f\&g Editores, 2011.

Francisco, Papa. “Laudato Si: sobre cuidado de la casa común”. Colombia: San Pablo, 2015.

Germanwatch. Índice de Riesgo Climático Global 2015. <https://germanwatch.org/es/download/10343.pdf>.

Gómez Sabaíni, Juan Carlos; Jiménez, Juan Pablo y Morán, Dalmiro. “El impacto fiscal de la explotación de los recursos naturales no renovables en los países de América Latina y el Caribe". Santiago de Chile: CEPAL, 2015.

Global Witness. ¿Cuántos más? El medio ambiente mortal de 2014. Intimidación y asesinato de activistas ambientales y de la tierra, con Honduras en primer plano. <//C:/Users/Usuario/ Downloads/Cuantos_mas_informe_gJ6Jht8.pdf $>$.

Gudynas, Eduardo. “Diez tesis urgentes sobre el nuevo extractivismo. Contextos y demandas bajo el progresismo sudamericano actual". En CAAP/CLAES, Extractivismo, politica y sociedad. Quito: Centro Andino de Acción Popular y Centro Latino Americano de Ecología Social, 2009. 
Gutiérrez, Hilda. Minería y movilización de recursos para el desarrollo social: el caso de Nicaragua. Managua: Fundación Internacional para el Desafío Económico Global \& Instituto de Investigación de las Naciones Unidas para el Desarrollo Social, 2015.

Hirschman, Albert. The Strategy of Economic Development. New Haven, Connecticut: Yale University Press, 1958.

Instituto Nacional de información de Desarrollo. VIII Censo de Población y IV Censo de Vivienda. Managua: Autor, 2005.

Jara, Cristian Emanuel. "La dimensión ecológica de las luchas campesinas: Disputas en torno al Ordenamiento Territorial de los Bosques Nativos en Santiago del Estero". Trabajo y sociedad 23 (2014): 389-405.

Klein, Naomi. Esto lo cambio todo. El capitalismo contra el clima. España: Paidós, 2015.

Luxemburgo, Rosa. La acumulación de capital. México: Grijalbo, 1978.

Machado Aráoz, Horacio. “Territorios y cuerpos en disputa. Extractivismo minero y ecología política de las emociones". Intersticios. Revista sociológica de pensamiento crítico 8.1 (2014): 56-71.

Martínez-Alier, Joan. “La justicia ambiental y el decrecimiento económico: una alianza entre dos movimientos". Ecología política 41 (2011): 45-54.

Martínez-Alier, Joan. “Justicia ambiental, sustentabilidad y valoración”. Ecología política: cuadernos de debate internacional, 21 (2001): 103-134.

Martínez-Alier, Joan. El ecologismo de los pobres. <http://www.envio.org.ni/articulo/718>. 1992

Martínez-Alier, Joan. "La interpretación ecologista de la historia socio-económica: algunos ejemplos andinos". Historia Social (1990): 137-162.

McAdam, Doug; Tarrow, Sidney y Tilly, Charles. Dinámica de la contienda política. Barcelona: Editorial Hacer, 2005.

McKinley, Andrés. Mitos y realidades de la minería de oro en Centroamérica. $<$ http://www.movimientom4.org/wp-content/docs/mitos-y-realidades-de-la-mineria-de-oro-en-centroamerica.pdf >. 2015.

Ministerio de Energías y Minas. Estadística de Minería Marzo 2015-2014. <http://www.mem. gob.ni/media/file/MINAS/Estadisticas/2015/resumenmarzo2015.pdf>.

Ministerio Agropecuario y Forestal e Instituto Nacional de Información de Desarrollo. IV Censo Nacional Agropecuario. Nicaragua, 2012.

Miranda, Wilfredo. Un oficial muerto, decenas de pobladores y policías heridos, incendian estación policial. Grave enfrentamiento en la Mina El Limón. Nicaragua, En Confidencia, Nicaragua, 2015. <https://www.google.com.ni/?client=firefox-b\#q=conflicto+minero $+\mathrm{en}+\mathrm{el}+\mathrm{Lim} \% \mathrm{C} 3 \% \mathrm{~B} 3 \mathrm{n} \% 2 \mathrm{C}+$ confidencial> .

Miranda, Wilfredo. "Batalla campal deja un muerto en Bonanza. Pobladores piden intervención del Gobierno para resolver la crisis". La Prensa de Nicaragua, 7 de mayo de 2015. <http://www.laprensa.com.ni/2015/05/07/departamentales/1827952-batalla-campaldeja-un-muerto-en-bonanza>.

Mojica-Mendieta, Francisco. De/colonialidad de la naturaleza, minería transnacional en Crucitas e Insurgentes de poder -saber fronterizo. Tesis doctorado. Jalisco México, 2014. <http://hdl. handle.net/11117/1269>.

Nicaragua, Gobierno de. Plan Nacional de Desarrollo Humano 2012-2016. Documento preliminar para consulta, 2012. 
Oxfam. Honduras el país más vulnerable al cambio climático. <http://www.laprensa.hn/honduras/766930-410/oxfam-honduras-el-pa\%C3\%ADs-m\%C3\%A1s-vulnerable-al-cambioclim\%C3\%A1tico>.

Padilla, Luis. “Estimación de Impactos Multiplicadores en la Economía Nicaragüense: Un Enfoque Insumo Producto". Revista de Economía y Finanzas 1 (2014): 77-106.

Pérez, Teresa. Minería y desarrollo en Nicaragua: una mirada feminista del caso de Rancho Grande. Tesis de Maestría en Perspectiva de Género y Desarrollo. Managua, Universidad Centroamericana de Nicaragua, 2015.

Porto-Gonçalves, Carlos Walter. "De saberes y de territorios: diversidad y emancipación a partir de la experiencia latino-americana”. Polis (Santiago) 8.22 (2009): 121-136.

ProNicaragua. Nicaragua. Discover the Mining Opportunities. Managua: ProNicaragua y Ministerio de Energía y Minas, 2015.

Rodríguez García, Roberto y Hesse, Monika. Camino se hace al andar. Colombia, Fundación Sembradores de Esperanza, 2000.

Sánchez, Mario; Castro, Douglas y Rodríguez, Rony. Ciudadanía y violencia. Una aproximación a sus múltiples expresiones en Nicaragua. Managua: Centro de Análisis Sociocultural y Editorial UCA, 2015.

Sassen, Saskia. Expulsiones. Brutalidad y complejidad en la economía global. Buenos Aires: Katz Ediciones, 2015.

Serjeant, Max. No a la Minería en Rancho Grande: An Investigation into the Relationship between Structure, Agency, Protest, and Mining in a Nicaraguan Village, 2015. <https:// openaccess.leidenuniv.nl/bitstream/handle/1887/33772/Thesis\%20-\%20FINISHED. pdf?sequence $=1>$.

Sosa, Tania. Rancho Grande. Una herencia natural y productiva amenazada por la minería. $<$ http://www. humboldt.org.ni/sites/default/files//BOLETIN\%20RANCHO\%20GRANDE_0.pdf>.

Spalding, Rose. "After Cafta: Anti-mining Movements, Investment Disputes, and New Organizational Territory". En Rose Spalding, Contesting Trade in Central America. Market Reform and Resistance. Texas: University of Texas Press, 2015. 157-187.

Spalding, Rose. Mining and Protest in Central America. Interpreting Alternative Outcomes. Paper presented at the XXXIV International Congress of the Latin American Studies Association, New York, NY, 2016.

Svampa, Maristella. Debates latinoamericanos. Indianismo, desarrollo, dependencia y populismo. Buenos Aires: Edhasa, 2016.

Tarrow, Sidney. El poder en movimiento. Los movimientos sociales, la acción colectiva y la política. Madrid: Alianza Editorial, 1997.

Toledo, Víctor; Garrido, David y Barrera-Basols, Narciso. “Conflictos socioambientales, resistencias ciudadanas y violencia neoliberal en México". Ecología Política 46 (2013): 115-124.

Veltmeyer, Henry y Petras, James. El neoextractivismo. ¿Un modelo posneoliberal de desarrollo o el imperialismo del siglo XXI? México D.F: Crítica, 2015.

Villafuerte, Daniel. "Neoextractivismo, megaproyectos y conflictividad en Guatemala y Nicaragua". Espiral (Guadalajara) 21.61 (2014): 109-141.

Wilde, Alexander. Las iglesias ante la violencia en América Latina. Los derechos humanos en el pasado y presente. México D.F: Flacso México y Center for Latin American \& Latino Studies, 2015.

Zibechi, Raúl. "Crisis civilizatoria, Encuentro Continental de los Pueblos del Abya Yala por el agua y la Pacha-mama”. (2011). 


\section{ANEXO}

\section{LISTA DE ENTREVISTADOS}

\begin{tabular}{|c|c|c|}
\hline N..$^{\circ}$ & $\begin{array}{l}\text { Personas entrevistadas/ } \\
\text { fecha de entrevista }\end{array}$ & Descripción \\
\hline 1 & Roberto Escorcia [22.10.15] & ADDAC de Matagalpa \\
\hline 2 & Samaria Marqueza [30.10.15] & Secretaria de Guardianes de Yaoska \\
\hline 3 & Vilma Pérez [21.10.15] & Miembro de Grupo Estratégico de Matagalpa \\
\hline 4 & Benigno Loáisiga [30.10.15] & Comunidad de Yaoska \\
\hline 5 & Elizabeth Chavarría [29.10.15] & $\begin{array}{c}\text { Delegada de la Palabra Comunidad San } \\
\text { Antonio de Kuskawas }\end{array}$ \\
\hline 6 & Ernesto Montenegro y Carlos Siles [21.10.15] & $\begin{array}{c}\text { Fundador de Guardianes de Yaosca. Ex secretario } \\
\text { político del FSLN en la comunidad. }\end{array}$ \\
\hline 7 & Carlos Siles [21.10.15] & $\begin{array}{l}\text { Fundador de Guardianes de Yaosca } \\
\text { y Radio Yaoska }\end{array}$ \\
\hline 8 & Francisco Pérez [30.10.15] & Pastor Iglesia Asamblea de Dios \\
\hline 9 & Harrington Gregorio Mayorga [30.10.15] & $\begin{array}{c}\text { Coordinador de oficina de Gestión Ambiental } \\
\text { de la Alcaldía de Rancho Grande }\end{array}$ \\
\hline 10 & Juan Herrera y [14.10.15] & Agrónomo de CICBATA \\
\hline 11 & Teresa Pérez [14.10.15] & Promotora de CICBATA \\
\hline 12 & Juana Loáisiga [30.10.15] & Líder de la comunidad Yaoska \\
\hline 13 & Luz Marina Zeledón [30.10.15] & $\begin{array}{c}\text { Ex-secretaria política, } \\
\text { Comunidad San Juan Pájaro }\end{array}$ \\
\hline 14 & María Auxiliadora [14.10.15] & Movimiento Comunal de Matagalpa \\
\hline 15 & Monseñor Sacasa [28.10.15] & Vicaria de la Diócesis de Matagalpa \\
\hline 16 & Monseñor Rolando Álvarez [28.10.15] & Obispo de la Diócesis de Matagalpa \\
\hline 17 & Padre Pablo Espinoza [21.10.2015] & Párroco de Rancho Grande \\
\hline 18 & Padre Teodoro Custer [30.10.15] & $\begin{array}{c}\text { Sacerdote Maryknoll y ex Primer Párroco } \\
\text { de Rancho Graden }\end{array}$ \\
\hline
\end{tabular}


N. ${ }^{\circ}$ Entrevistas a Expertos

$1 \quad$ Andrés McKinley

2 Mónica Bruckmann

( Uni

3 Joan Martínez Alier

Uno de los fundadores de la Economía Ecológica, catedrático del Departamento de Economía e Historia Económica Universidad Autónoma de Barcelona. Miembro de Comité Científico de la Agencia Europea de Medio Ambiente.

4 Tania Sosa Oficial de incidencia en el tema de industria del Centro Humboldt.

\section{Siglas}

ADDAC: Asociación para la Diversificación y Desarrollo Agrícola.

CELAM: Consejo Episcopal Latinoamericano.

CEN: Conferencia Episcopal de Nicaragua.

CEPAL: Comisión Económica para América Latina y el Caribe.

GIZ: Deutsche Gesellschaft für Internationale Zusammenarbeit (Cooperación Alemana). FSLN: Frente Sandinista de Liberación Nacional.

MASSD: Movimiento Ambiental Salvamos Santo Domingo.

MINESA: Sociedad Minera Santander S.A.

RACCN: Región Autónoma Caribe Norte. 
Mario Sánchez González. Nicaragüense, es director del Centro de Análisis Socio Cultural (CASC) de la Universidad Centroamericana de Nicaragua. En El Salvador acompañó a los procesos de reinserción y desarrollo comunitario de excombatientes y repatriados en marco del cumplimiento de los Acuerdos de Paz, trabajó como investigador y formador en el tema de construcción de paz y transformación de conflictos, prevención de violencia juvenil, desarrollo rural y en derechos humanos, y fue coordinador de la Asociación Pro-Búsqueda de Niñas y Niños Desaparecidos, organización de víctimas y familiares que ha luchado incansablemente por la reivindicación de sus derechos, fundada por el Padre Jon de Cortina sj, cuya labor fue reconocida con el Premio Internacional en Derechos Humanos Jaime Brunnet 2007. Ha sido docente y catedrático de la Universidad Centroamericana José Simeón Cañas de El Salvador en la maestría en Desarrollo Local.

Entre sus publicaciones en coautoría caben destacar: Movimientos sociales y acción colectiva en Nicaragua: entre la identidad, autonomía y subordinación (2016); Tropas salvadoreñas en Irak: implicaciones éticas según Kant (2016); Ciudadanía y Violencia. Una aproximación a sus múltiples expresiones en Nicaragua (2015); Participación de la Sociedad civil en el marco de la integración regional centroamericana (2011); Iglesia y Ciudadanía: una agenda pendiente en Nicaragua (2012); Capítulo Nicaragua y su articulación con el CC-SICA (2012) y Conflictos del pasado y nuevo escenarios de violencia en Centroamérica (2010).

Contacto: mario.sanchez@uca.edu.ni 
